Supporting Information for:

\title{
Biological Characterization and in Vivo Assessment of the Activity of a New Synthetic Macrocyclic Antifungal Compound
}

Davide Deodato, ${ }^{\dagger}$ Giorgio Maccari,${ }^{\dagger}$ Filomena De Luca,${ }^{\star}$ Stefania Sanfilippo, ${ }^{\dagger}$ Alexandru Casian, ${ }^{\dagger}$ Riccardo Martini, ${ }^{\dagger}$ Silvia D’Arezzo, ${ }^{\S}$ Carlo Bonchi, $\|$ Francesca Bugli, ${ }^{\perp}$ Brunella Posteraro, ${ }^{\#}$ Patrick Vandeputte, ${ }^{\nabla}$ Dominique Sanglard, ${ }^{\nabla}$ Jean-Denis Docquier, ${ }^{\ddagger}$ Maurizio Sanguinetti, ${ }^{,}{ }^{\#}$ Paolo Visca," Maurizio Botta, $*, \dagger, \circ, \delta$

\section{CONTENTS}

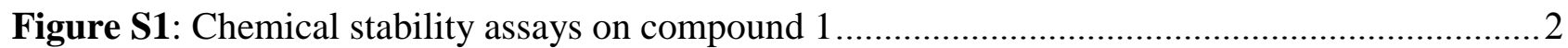

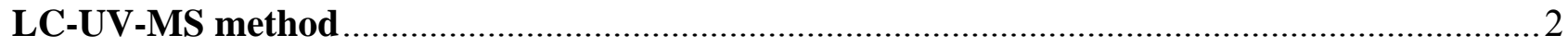

Table S1: Gene commonly upregulated by Compound 1 in C. albicans at 15 and 45 min time points .4

Table S2: Gene commonly downregulated by Compound 1 in C. albicans at 15 and 45 min time points 7

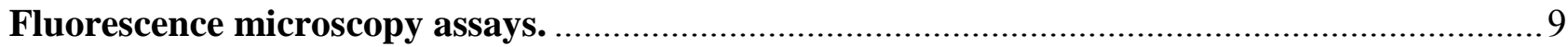

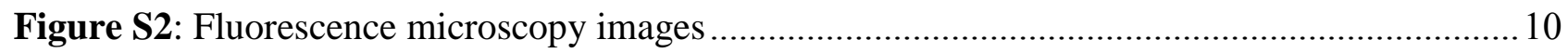

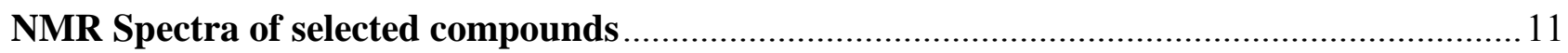




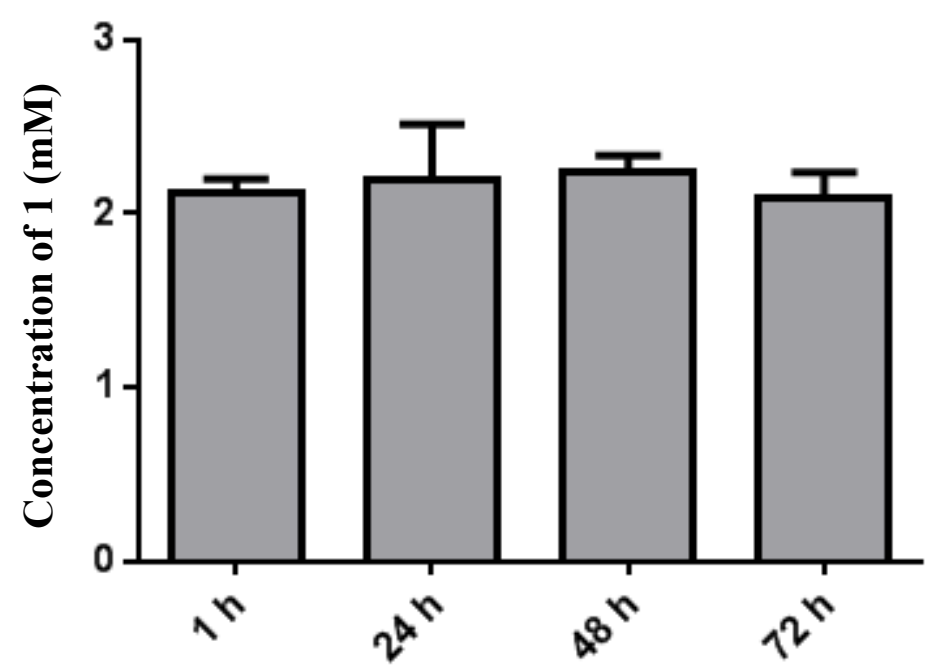

Figure S1: Chemical stability assays on compound 1 after incubation in RMPI-1640 buffer at 30 ${ }^{\circ} \mathrm{C}$. Sample were collected at 1, 24, 48 and $72 \mathrm{~h}$ time points and analyzed with the LC-UV-MS method beneath. Initial concentration of compound $\mathbf{1}$ is $2 \mathrm{mM}$. Each aliquot was analyzed in triplicate.

\section{LC-UV-MS method}

LC analysis were performed with an Agilent 1100 LC/MSD VL system (G1946C) (Agilent Technologies, Palo Alto, CA) consisted of a vacuum solvent degassing unit, a binary high-pressure gradient pump, a 1100 series UV detector, and a 1100 MSD model VL benchtop mass spectrometer.

Chromatographic profiles were obtained using a Kinetex C18 column -100 x 4.6 mm(Phenomenex) with $2.6 \mu \mathrm{m}$ particle size and gradient elution: eluent A being ACN and eluent B consisting of water. The analysis started with $10 \%$ of eluent A, which was rapidly increased up to $60 \%$ in $15 \mathrm{~min}$, then remaining at $60 \%$ in $20 \mathrm{~min}$. The flow rate was $0.4 \mathrm{~mL} \mathrm{~min}^{-1}$ and injection volume was $20 \mu \mathrm{L}$.

The Agilent 1100 series mass spectra detection (MSD) single-quadrupole instrument was equipped with the orthogonal spray API-ES (Agilent Technologies, Palo Alto, CA). Nitrogen was used as 
nebulizing and drying gas. The pressure of the nebulizing gas, the flow of the drying gas, the capillary voltage, the fragmentor voltage and desolvation temperature were set at $40 \mathrm{psi}, 9 \mathrm{~L} / \mathrm{min}$, $3000 \mathrm{~V}, 70 \mathrm{~V}$, and $350^{\circ} \mathrm{C}$, respectively. UV detection was monitored at $210 \mathrm{~nm}$. The LC-ESI-MS determination was performed by operating the MSD in positive ion mode. Spectra were acquired over the scan range $m / z 100-1500$ using a step size of $0.1 \mathrm{u}$. 
Table S1: Gene commonly upregulated by Compound 1 in C. albicans at 15 and 45 min time points

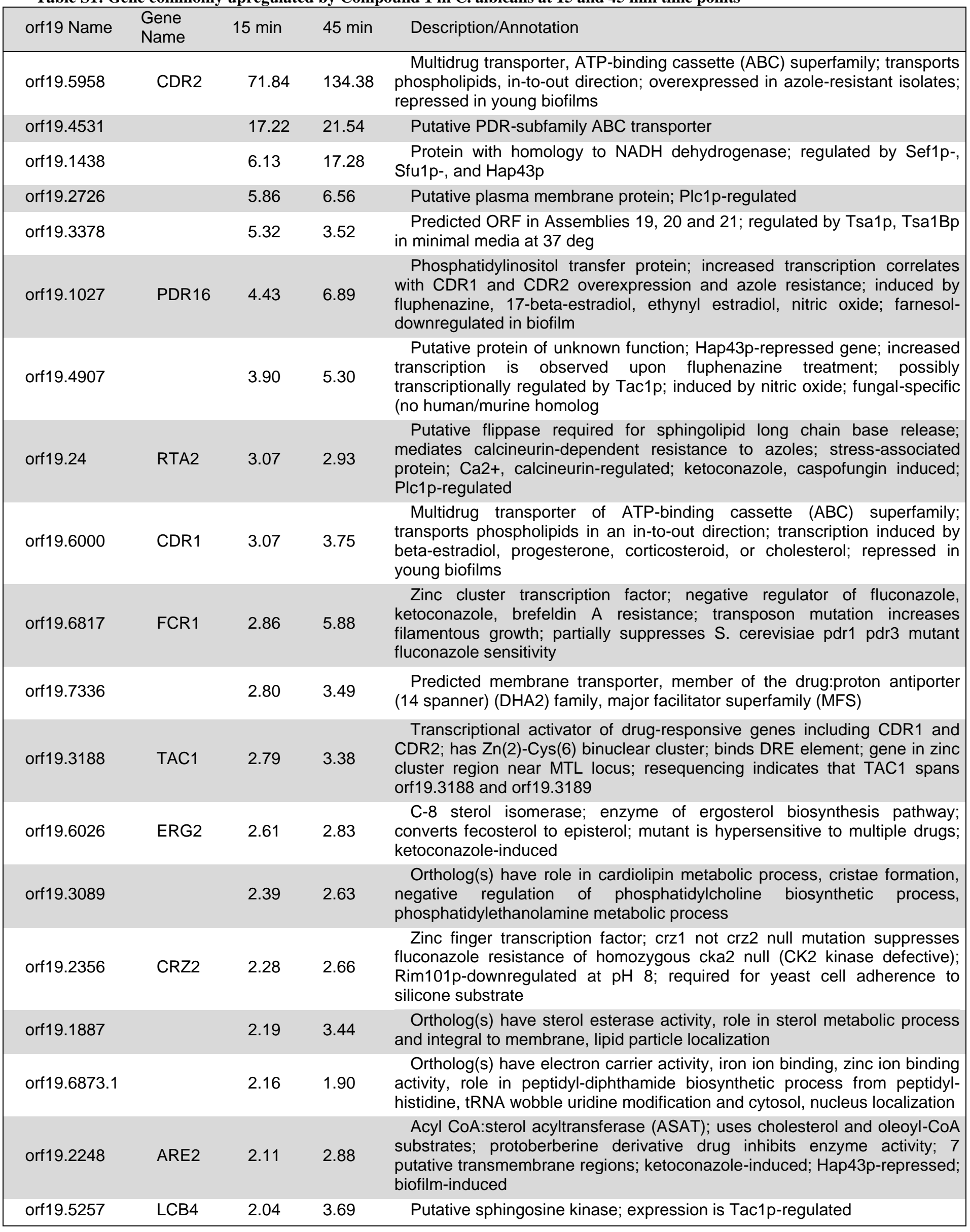




\begin{tabular}{|c|c|c|c|c|}
\hline orf19.4886 & & 2.02 & 4.86 & Putative adhesin-like protein; Hap43p-repressed gene \\
\hline orf19.86 & & 2.02 & 2.51 & $\begin{array}{l}\text { Putative glutathione peroxidase; peroxide-induced; induced in response to } \\
\text { peroxide, exposure to neutrophils and macrophage blood fractions; } \\
\text { downregulated during infection of macrophages }\end{array}$ \\
\hline orf19.6660 & & 2.01 & 3.11 & $\begin{array}{l}\text { Putative protein of unknown function; mRNA binds to She3p; Hap43p- } \\
\text { repressed gene; biofilm-induced }\end{array}$ \\
\hline orf19.93 & & 1.97 & 3.37 & $\begin{array}{l}\text { Putative mitochondrial intermembrane space protein; shows colony } \\
\text { morphology-related gene regulation by Ssn6p; regulated by Sef1p-, Sfu1p-, } \\
\text { and Hap43p }\end{array}$ \\
\hline orf19.1430 & & 1.93 & 5.14 & Ortholog of C. parapsilosis CDC317 : CPAR2_402120 \\
\hline orf19.1719 & SGA1 & 1.93 & 1.95 & Putative glucoamylase; induced in oralpharyngeal candidasis \\
\hline orf19.5290 & & 1.91 & 5.00 & Hap43p-induced gene; transcription is negatively regulated by Sfu1p \\
\hline orf19.909 & STP4 & 1.90 & 1.59 & $\begin{array}{l}\text { Putative transcription factor with zinc finger DNA-binding motif; induced in } \\
\text { core caspofungin response; shows colony morphology-related gene } \\
\text { regulation by Ssn6p; induced by 17-beta-estradiol, ethynyl estradiol }\end{array}$ \\
\hline orf19.2049 & & 1.88 & 1.75 & $\begin{array}{l}\text { Plasma membrane-associated protein; heterozygous null mutant displays } \\
\text { sensitivity to virgineone }\end{array}$ \\
\hline orf19.3479 & & 1.80 & 1.83 & \\
\hline orf19.5713 & YMX6 & 1.79 & 2.55 & $\begin{array}{l}\text { Putative NADH dehydrogenase; macrophage-downregulated gene; } \\
\text { induced by nitric oxide }\end{array}$ \\
\hline orf19.2021 & HGT8 & 1.78 & 1.67 & $\begin{array}{l}\text { High-affinity glucose transporter of the major facilitator superfamily; } 20 \\
\text { members in the C. albicans glucose transporter family; } 12 \text { probable } \\
\text { membrane-spanning segments; gene has intron; expressed in rich medium; } \\
\text { biofilm-induced }\end{array}$ \\
\hline orf19.6007 & & 1.77 & 1.64 & $\begin{array}{l}\text { Predicted ORF in Assemblies 19, } 20 \text { and 21; decreased expression in } \\
\text { response to prostaglandins }\end{array}$ \\
\hline orf19.5905 & & 1.76 & 1.55 & Hap43p-induced gene; induced upon biofilm formation \\
\hline orf19.2431 & & 1.74 & 2.72 & $\begin{array}{l}\text { Dubious open reading frame, not conserved in Candida species; } \\
\text { transcription is induced in response to alpha pheromone in SpiderM } \\
\text { medium; mRNA binds She } 3 p\end{array}$ \\
\hline orf19.5126 & & 1.71 & 1.69 & Putative adhesin-like protein \\
\hline orf19.2231 & & 1.69 & 3.11 & Ortholog of C. parapsilosis CDC317 : CPAR2_104360 \\
\hline orf19.2590 & & 1.66 & 1.70 & $\begin{array}{l}\text { Putative dethiobiotin synthetase; transcription is upregulated in clinical } \\
\text { isolates from HIV+ patients with oral candidiasis; Hap43p-repressed gene; } \\
\text { GlcNAc-induced protein }\end{array}$ \\
\hline orf19.7386 & & 1.66 & 1.72 & Ortholog(s) have ribosome binding activity \\
\hline orf19.1957 & CYC3 & 1.65 & 1.65 & $\begin{array}{l}\text { Cytochrome c heme lyase, mitochondrial; gene also encodes antigenic } \\
\text { cell-wall protein; mRNA more abundant in filaments than yeast-form; } \\
\text { induced on polystyrene adherence, interaction with macrophage; N- } \\
\text { glycosylation, } 2 \text { heme-binding motifs }\end{array}$ \\
\hline orf19.2568 & IFU5 & 1.63 & 2.58 & $\begin{array}{l}\text { Predicted membrane protein; estradiol-induced; increased transcription } \\
\text { associated with CDR1 and CDR2 overexpression or fluphenazine treatment; } \\
\text { putative drug-responsive regulatory site; similar to S. cerevisiae Wwm1p; } \\
\text { Hap43p-repressed gene }\end{array}$ \\
\hline orf19.454 & SFL1 & 1.61 & 1.56 & $\begin{array}{l}\text { Transcription factor involved in negative regulation of flocculation and } \\
\text { filamentous growth; induced in core caspofungin response }\end{array}$ \\
\hline orf19.3104 & YDC1 & 1.61 & 2.76 & $\begin{array}{l}\text { Protein with Mob2p-dependent hyphal regulation; transcription is } \\
\text { regulated by Nrg1p and Mig1p; Hap43p-repressed gene }\end{array}$ \\
\hline orf19.2238 & LTE1 & 1.60 & 1.60 & $\begin{array}{l}\text { Protein similar to } S \text {. cerevisiae Lte1p; transcription is repressed in } \\
\text { response to alpha pheromone in SpiderM medium }\end{array}$ \\
\hline orf19.2754 & & 1.58 & 3.01 & $\begin{array}{l}\text { Ortholog(s) have protein transporter activity, role in protein import into } \\
\text { mitochondrial inner membrane and cytosol, mitochondrial intermembrane } \\
\text { space protein transporter complex, nucleus localization }\end{array}$ \\
\hline orf19.4847 & & 1.56 & 1.67 & ORF Predicted by Annotation Working Group; overlaps orf19.4846 \\
\hline orf19.6627 & & 1.52 & 2.03 & Predicted ORF in Assemblies 19, 20 and 21; possibly transcriptionally \\
\hline
\end{tabular}


regulated upon hyphal formation

orf19.4932

orf19.3665
$1.52 \quad 1.65$

1.52

Ortholog(s) have role in mitochondrial translation and mitochondrion localization

1.74 Hap43p-induced gene; ortholog of S. cerevisiae SET6, a SET domain protein of unknown function 
Table S2: Gene commonly downregulated by Compound 1 in $C$. albicans at 15 and 45 min time points

\begin{tabular}{|c|c|c|c|c|}
\hline orf19 Name & $\begin{array}{l}\text { Gene } \\
\text { Name }\end{array}$ & $15 \mathrm{~min}$ & $45 \mathrm{~min}$ & Description/Annotation \\
\hline orf19.3117 & CSA2 & -3.06 & -5.69 & $\begin{array}{l}\text { Extracellular-associated protein; downregulated by } \operatorname{Rim} 101 \mathrm{p} \text { at } \mathrm{pH} 8 \text {; } \\
\text { regulated by Tsa1p, Tsa1Bp in minimal media at } 37 \mathrm{deg} \text {; induced by } \\
\text { ketoconazole and nitric oxide; Hap43p-induced }\end{array}$ \\
\hline orf 19.34 & & -2.19 & -2.38 & $\begin{array}{l}\text { Glycerophosphoinositol permease, involved in utilization of } \\
\text { glycerophosphoinositol as a phosphate source; fungal-specific (no human or } \\
\text { murine homolog); transcription negatively regulated by Rim101p; virulence- } \\
\text { group-correlated expression; }\end{array}$ \\
\hline orf 19.4211 & FET3 & -1.99 & -2.12 & $\begin{array}{l}\text { Multicopper oxidase; required for growth in low-iron; required for } \\
\text { prostaglandin E2 production; functional homolog of S. cerevisiae Fet } 3 p \text {; } \\
\text { ketoconazole, caspofungin, amphotericin B repressed; regulated by Sef1p, Sfu1p, } \\
\text { and Hap43p }\end{array}$ \\
\hline orf19.5334 & & -1.98 & -2.38 & $\begin{array}{l}\text { Biofilm- and planktonic growth-induced gene; transcription regulated upon } \\
\text { yeast-hyphal switch }\end{array}$ \\
\hline orf19.5616 & & -1.92 & -3.84 & Ortholog of C. parapsilosis CDC317 : CPAR2_503850 \\
\hline orf 19.4450 .1 & & -1.86 & -4.40 & $\begin{array}{l}\text { Protein conserved among the fungal CTG-clade; gene contains two adjacent } \\
\text { upstream SRE-1 elements; highly up-regulated in cecum-grown cells in a Cph2p- } \\
\text { dependent manner; Hap43p-repressed gene; biofilm-induced }\end{array}$ \\
\hline orf19.1207 & & -1.86 & -3.04 & \\
\hline orf19.1847 & ARO10 & -1.85 & -1.61 & $\begin{array}{l}\text { Aromatic decarboxylase of the Ehrlich fusel oil pathway of aromatic alcohol } \\
\text { biosynthesis; pH-regulated (alkaline downregulated); protein abundance is } \\
\text { affected by URA3 expression in the CAI- } 4 \text { strain background }\end{array}$ \\
\hline orf19.5316 & FGR29 & -1.76 & -2.82 & $\begin{array}{l}\text { Protein lacking an ortholog in S. cerevisiae; transposon mutation affects } \\
\text { filamentous growth }\end{array}$ \\
\hline orf 19.4067 & FGR18 & -1.73 & -3.06 & $\begin{array}{l}\text { Protein lacking an ortholog in S. cerevisiae; transposon mutation affects } \\
\text { filamentous growth }\end{array}$ \\
\hline orf19.1171 & & -1.69 & -1.57 & Ortholog of C. parapsilosis CDC317 : CPAR2_208080 \\
\hline orf19.3049 & & -1.68 & -2.76 & $\begin{array}{l}\text { Ortholog(s) have protein kinase activity, role in activation of bipolar cell } \\
\text { growth, ascospore wall assembly, protein phosphorylation and cell division site, } \\
\text { cytosol, nucleus, prospore membrane localization }\end{array}$ \\
\hline orf19.1664 & & -1.65 & -1.81 & Protein of unknown function; expression downregulated in an ssr1 null mutant \\
\hline orf19.3895 & CHT2 & -1.63 & -1.95 & $\begin{array}{l}\text { GPI-linked chitinase required for normal filamentous growth; downregulated } \\
\text { in core caspofungin response; induced in yeast cells; fluconazole, Cyr1p-, Efg1p- } \\
\text {, pH-regulated; mRNA binds She } 3 p \text {, is localized to yeast-form buds and hyphal } \\
\text { tips }\end{array}$ \\
\hline orf19.7586 & CHT3 & - & -2.89 & $\begin{array}{l}\text { Major chitinase; secreted; functional homolog of S. cerevisiae Cts1p; } 4 \mathrm{~N} \text { - } \\
\text { glycosylation motifs; possible O-mannosylation; putative signal peptide; hyphal- } \\
\text { repressed; farnesol upregulated in biofilm; regulated by Efg1p, Cyr1p, Ras1p }\end{array}$ \\
\hline orf19.1187 & $\mathrm{CPH} 2$ & -1.62 & -1.95 & $\begin{array}{l}\text { Myc-bHLH family transcriptional activator of hyphal growth; directly } \\
\text { regulates Tec1p, which regulates hypha-specific genes; probably homodimeric, } \\
\text { phosphorylated; required for wild-type levels of Candida colonization of the } \\
\text { mouse GI tract }\end{array}$ \\
\hline orf19.2846 & & -1.61 & -1.51 & $\begin{array}{l}\text { Hap43p-repressed gene; induced in core caspofungin response; transcription } \\
\text { regulated upon yeast-hyphal switch }\end{array}$ \\
\hline orf19.2333 & & -1.60 & -1.56 & $\begin{array}{l}\text { Ortholog(s) have role in retrograde transport, endosome to Golgi and cytosol, } \\
\text { late endosome, nucleus localization }\end{array}$ \\
\hline orf19.1935 & & -1.56 & -1.70 & \\
\hline orf 19.4975 & HYR1 & -1.56 & -1.59 & Hyphal-induced GPI-anchored cell wall protein; macrophage-induced; \\
\hline
\end{tabular}




\begin{tabular}{|c|c|c|c|}
\hline & & & $\begin{array}{l}\text { repressed by neutrophil-co-culture; resistance to killing by neutrophils, azole } \\
\text { resistance; regulated by } \operatorname{Rfg} 1 \mathrm{p}, \operatorname{Efg} 1 \mathrm{p}, \mathrm{Nrg} 1 \mathrm{p} \text {, Tup1p, Cyr1p, Bcr1p, Hap43p; } \\
\text { biofilm-induced }\end{array}$ \\
\hline orf19.2227 & -1.54 & -1.99 & Biofilm-induced gene; repressed by nitric oxide \\
\hline orf19.1582 & -1.53 & -1.64 & $\begin{array}{l}\text { Predicted membrane transporter, member of the drug:proton antiporter (12 } \\
\text { spanner) (DHA1) family, major facilitator superfamily (MFS); mRNA binds to } \\
\text { She3p }\end{array}$ \\
\hline orf19.6148 & -1.53 & -1.65 & Has domain(s) with predicted ATP binding activity \\
\hline orf19.6119 & -1.53 & -1.59 & Ortholog of C. parapsilosis CDC317 : CPAR2_204390 \\
\hline orf 19.6636 & -1.51 & -1.59 & $\begin{array}{l}\text { Ortholog of S. cerevisiae : YPR084W, C. glabrata CBS138: CAGL0K07898g } \\
\text { and C. parapsilosis CDC317 : CPAR2_702430 }\end{array}$ \\
\hline orf19.921 & -1.51 & -2.39 & $\begin{array}{l}\text { Transcriptional regulator required for morphogenesis induced by elevated } \\
\text { temperature or Hsp90 compromise; acts downstream of Pcl1p }\end{array}$ \\
\hline orf19.6398 & -1.51 & -4.09 & Predicted ORF in Assemblies 19, 20 and 21; induced by nitric oxide \\
\hline
\end{tabular}




\section{Fluorescence microscopy assays.}

Samples of C. albicans ATCC 60193 and C. neoformans cultures $(50 \mu \mathrm{L})$ were treated for $24 \mathrm{~h}$ with compounds 2 and $\mathbf{3}(80 \mu \mathrm{M}$ and $5 \mu \mathrm{M})$, extensively washed with saline, and examined under UV light using of Axio Imager M1 (Carl Zeiss, Germany) fluorescence microscope (Figure S1). 

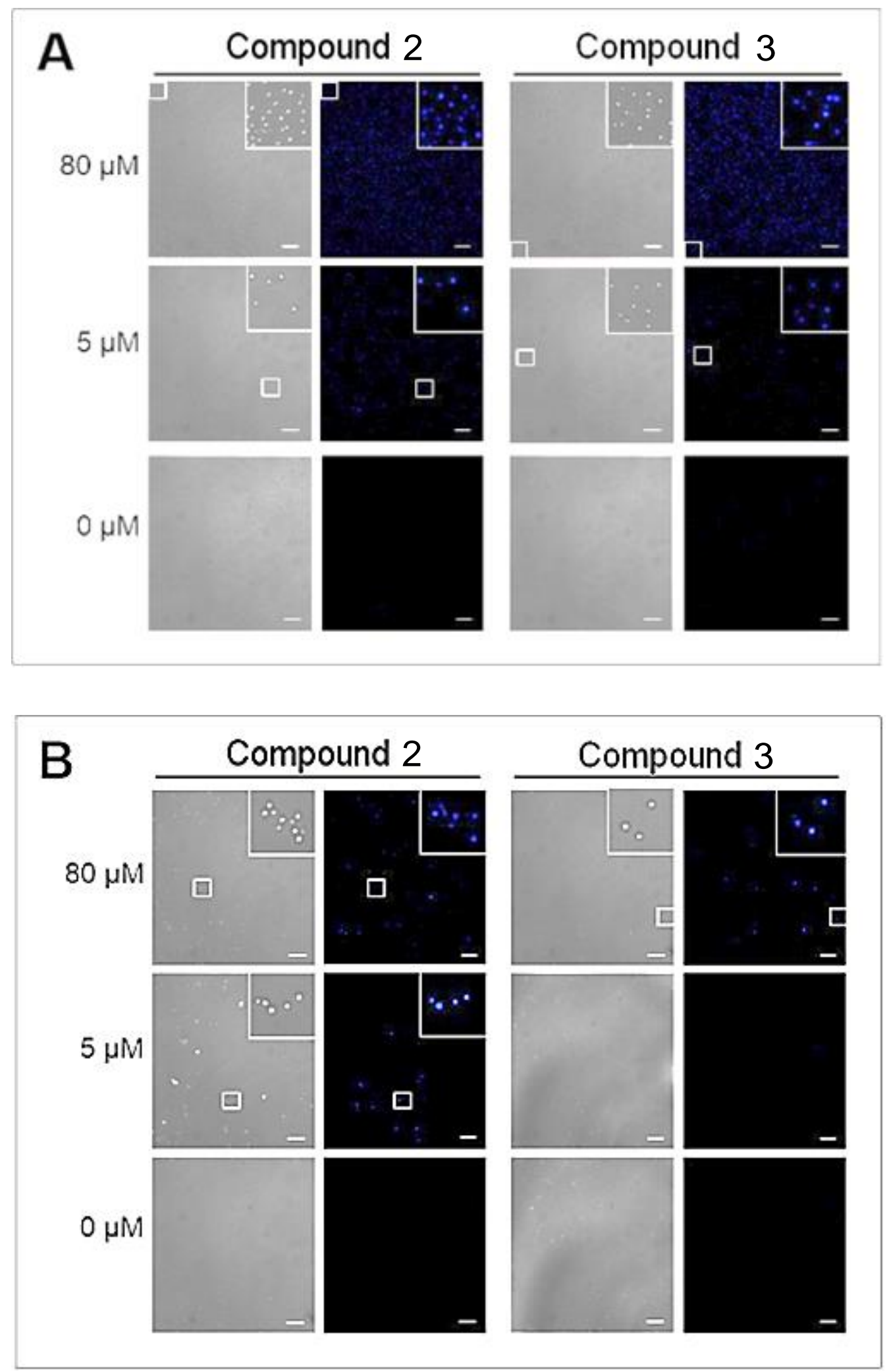

Figure S2: Fluorescence microscopy of C. albicans ATCC 60193 (A) and C. neoformans (B) treated with sub-MIC concentrations of compound $\mathbf{2}$ and compound $\mathbf{3}$, as illustrated in the panels. Magnification 20x. Scale bar: $50 \mu \mathrm{m}$. 
NMR Spectra of selected compounds

Compound $7{ }^{1} \mathrm{HNMR} \mathrm{CDCl}{ }_{3}$
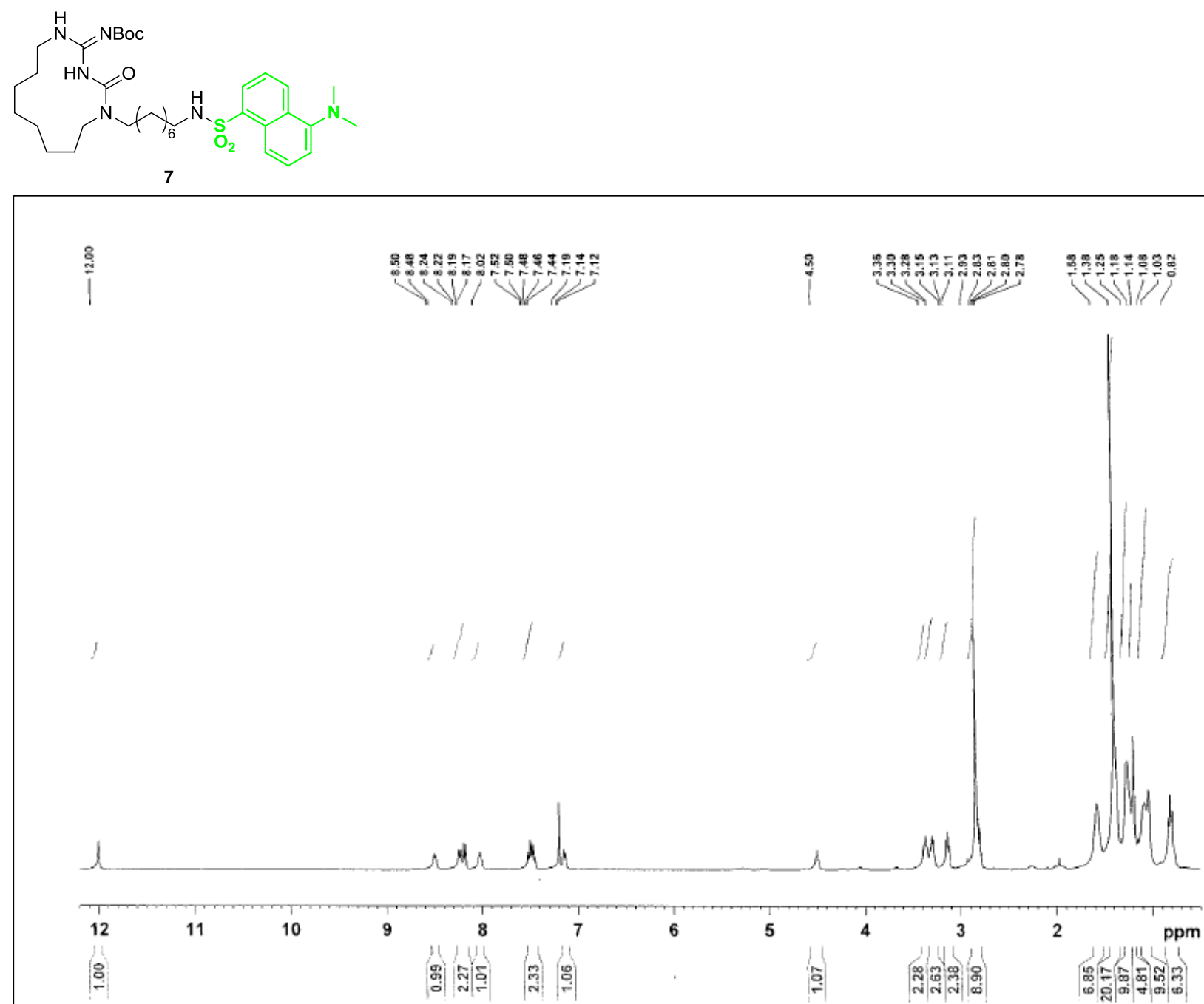
Compound $10{ }^{1} \mathrm{HNMR} \mathrm{CDCl}_{3}$

$\int_{Y^{N}}^{\mathrm{N}} Y^{\mathrm{NBoc}}$

10

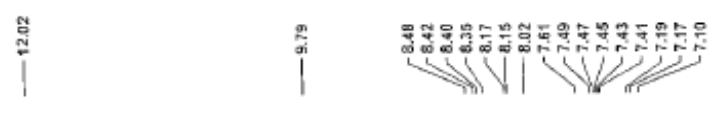

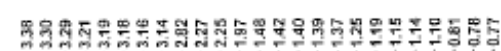

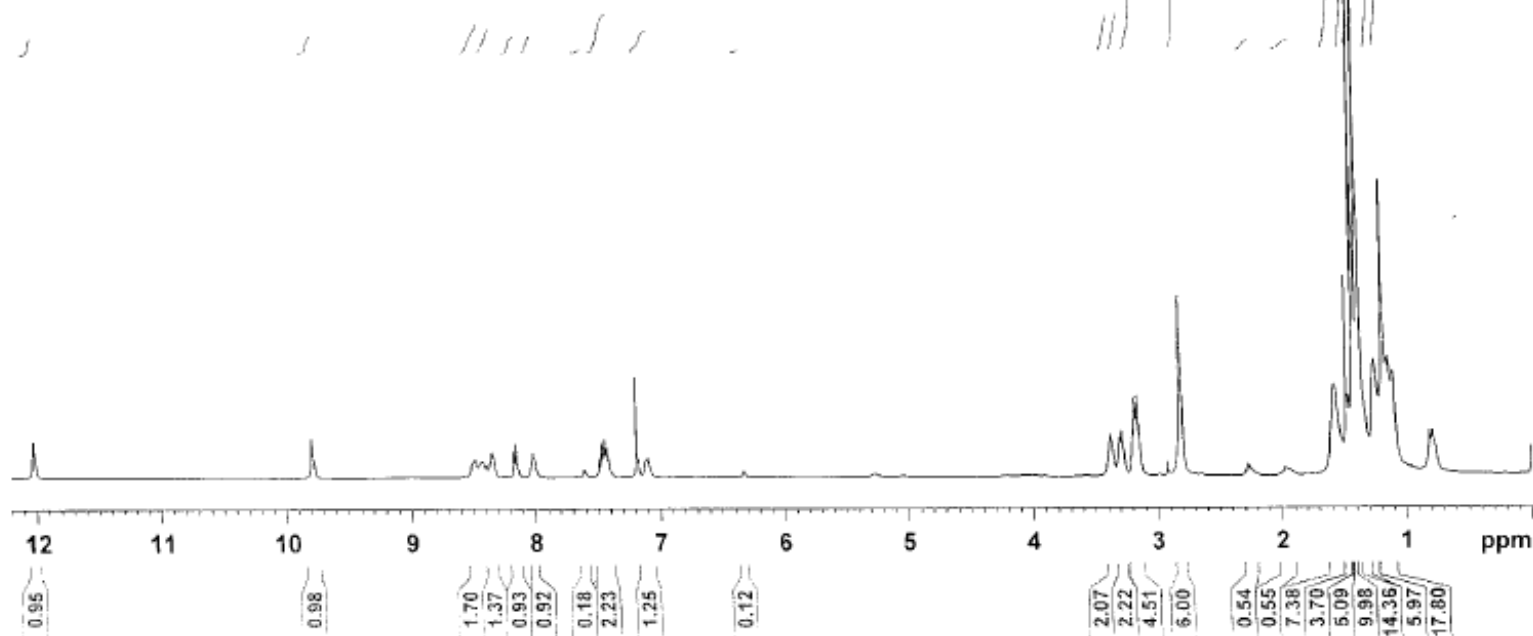


Compound 2

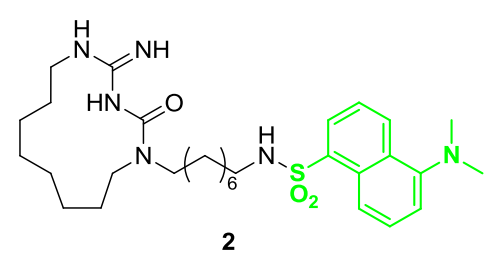

${ }^{1} \mathrm{HNMR} \mathrm{CDCl}_{3}$

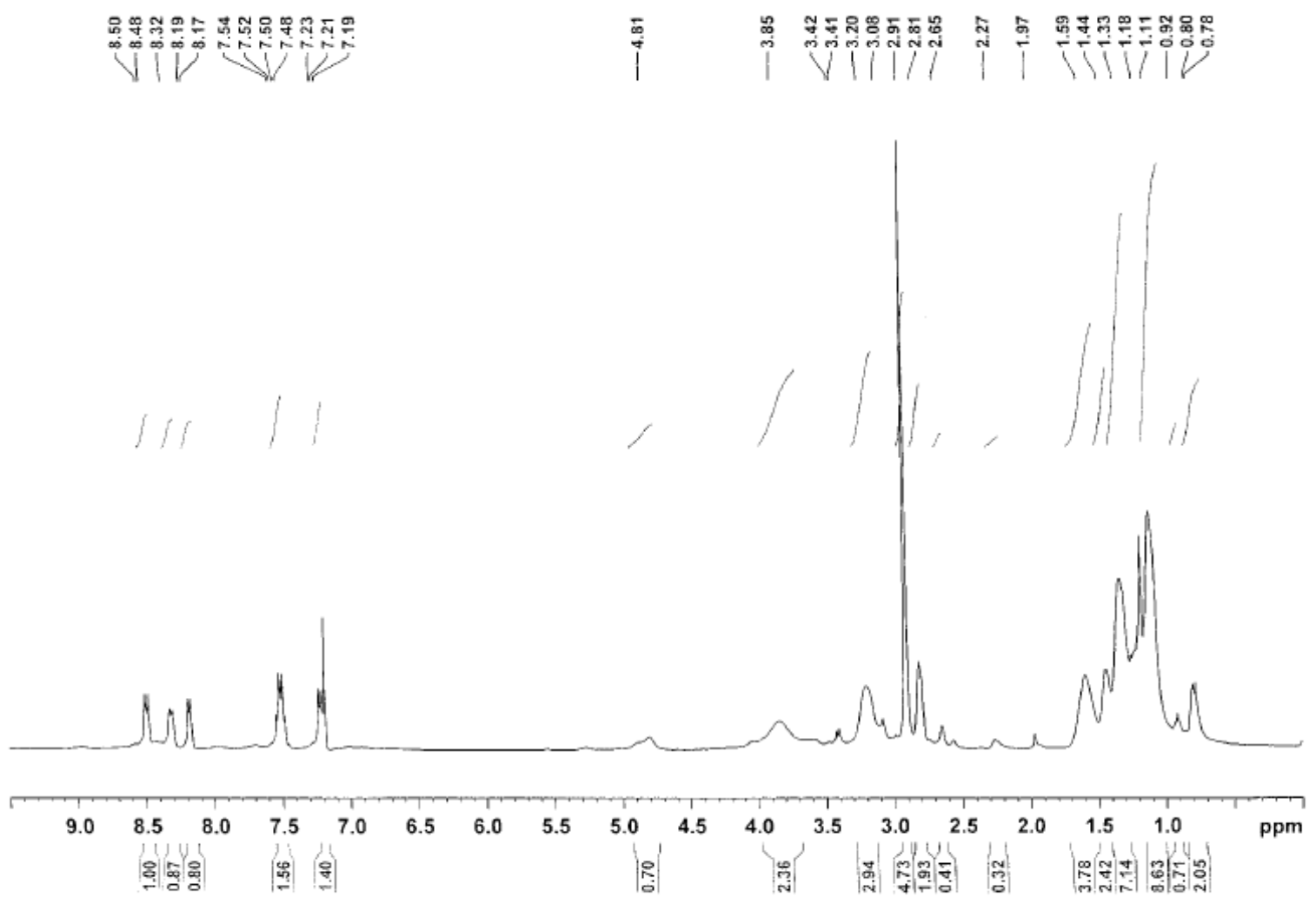


${ }^{13} \mathrm{CNMR} \mathrm{CDCl}_{3}$

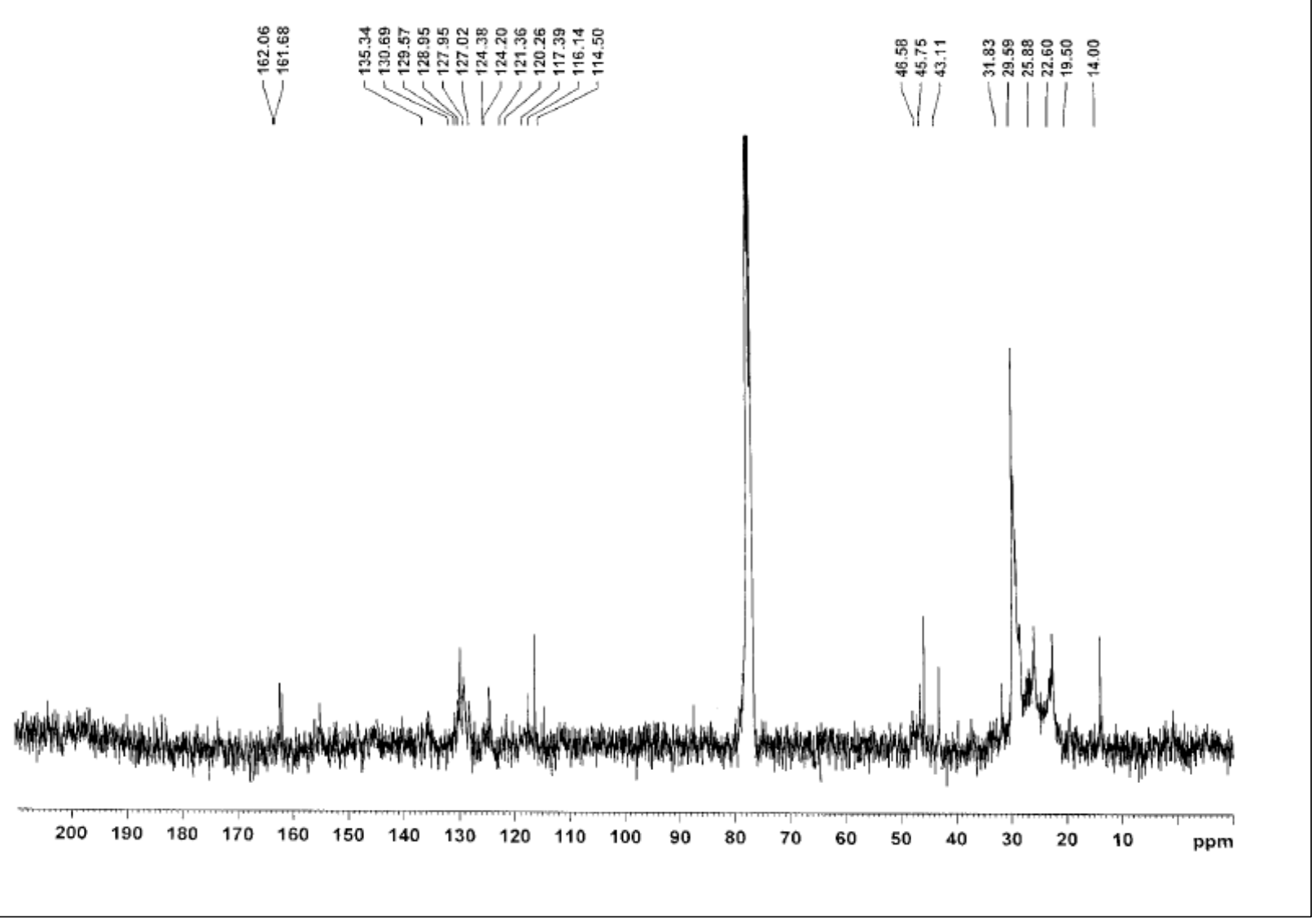


Compound $3{ }^{1} \mathrm{HNMR} \mathrm{CD}_{3} \mathrm{OD}$
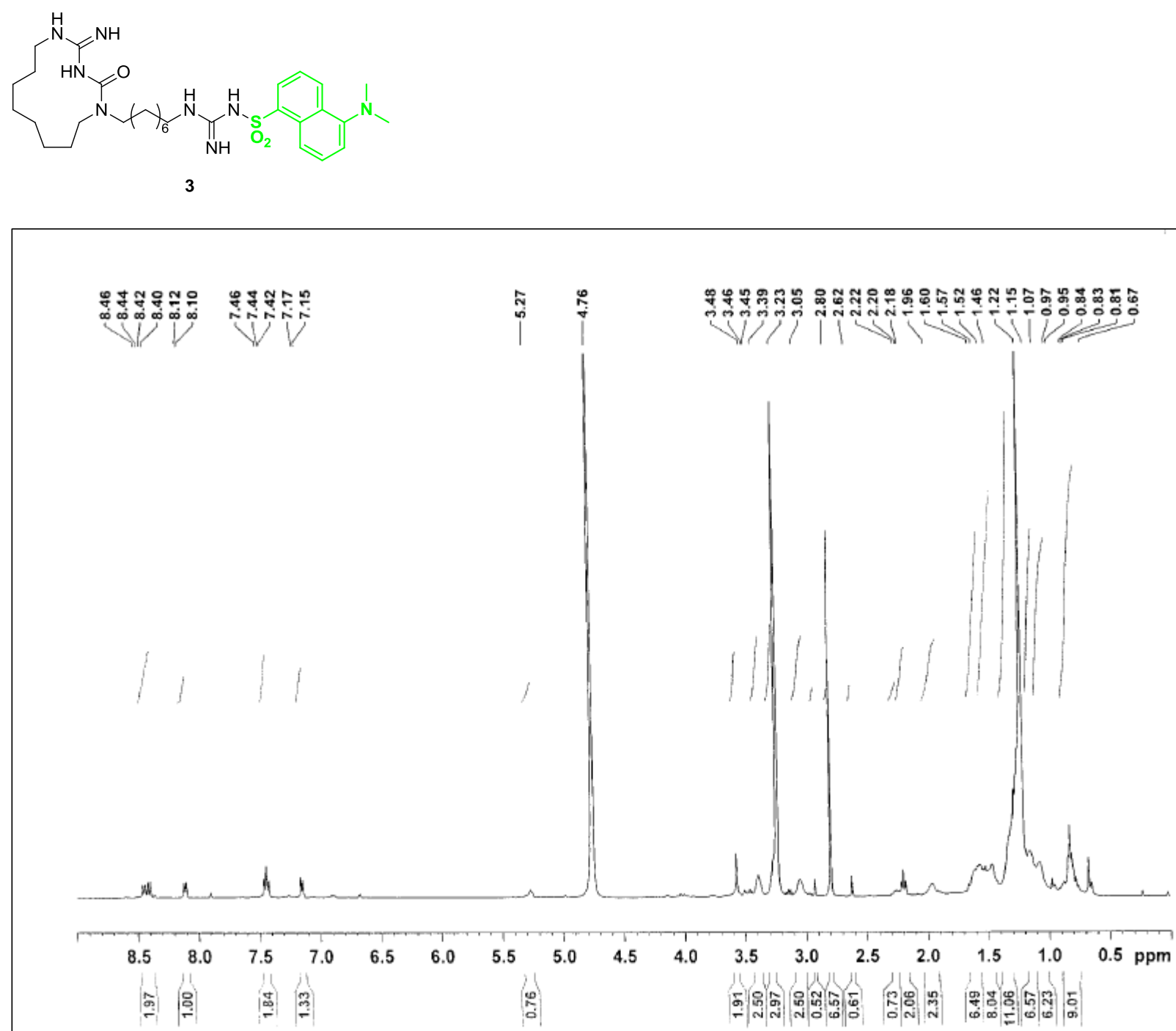
${ }^{13} \mathrm{CNMR} \mathrm{CDCl}_{3}$

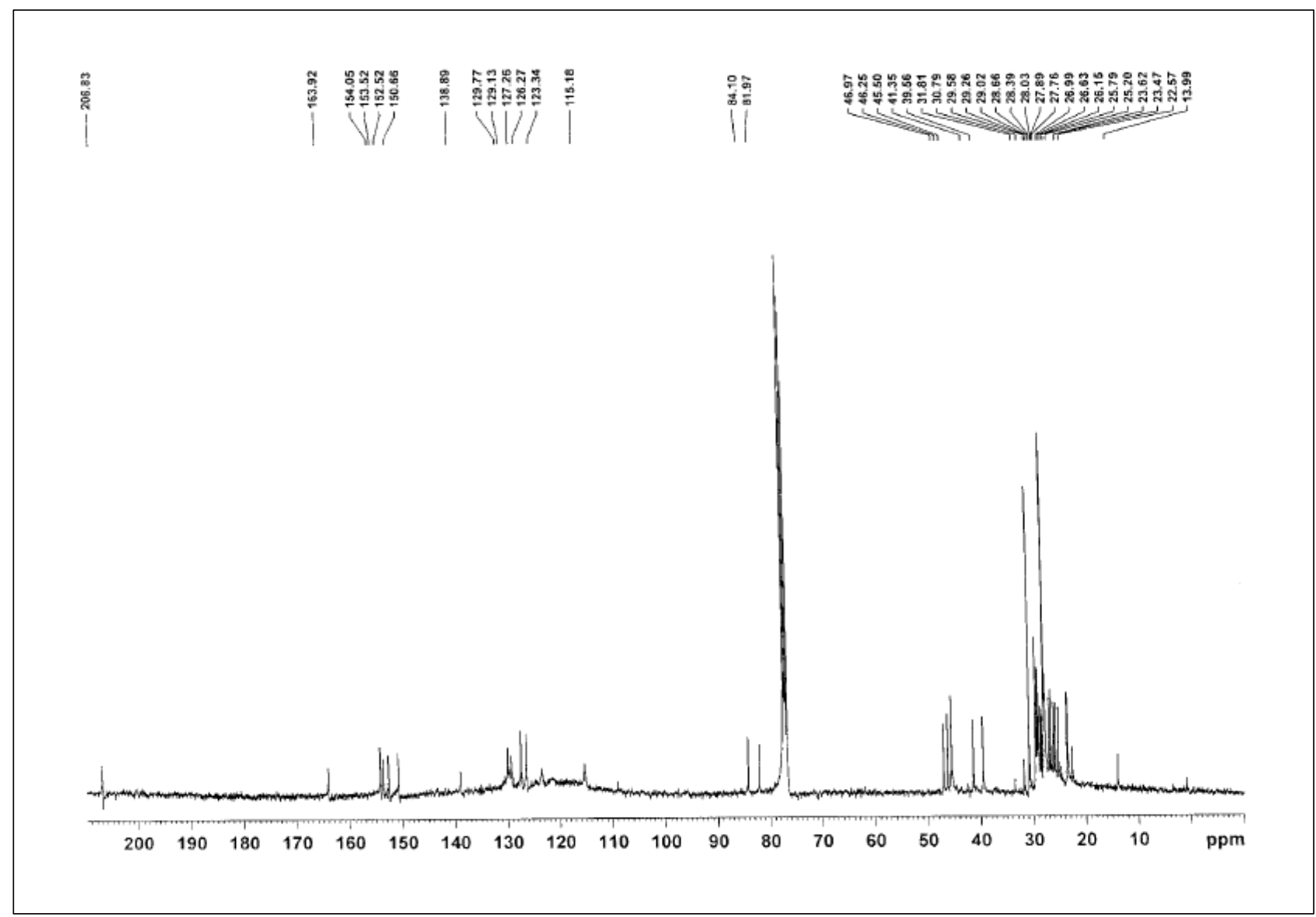


Compound 12, ${ }^{1} \mathrm{HNMR} \mathrm{CDCl}_{3}$<smiles>O=Cc1ccc(OCCCN2C(=O)c3ccccc3C2=O)cc1O</smiles>

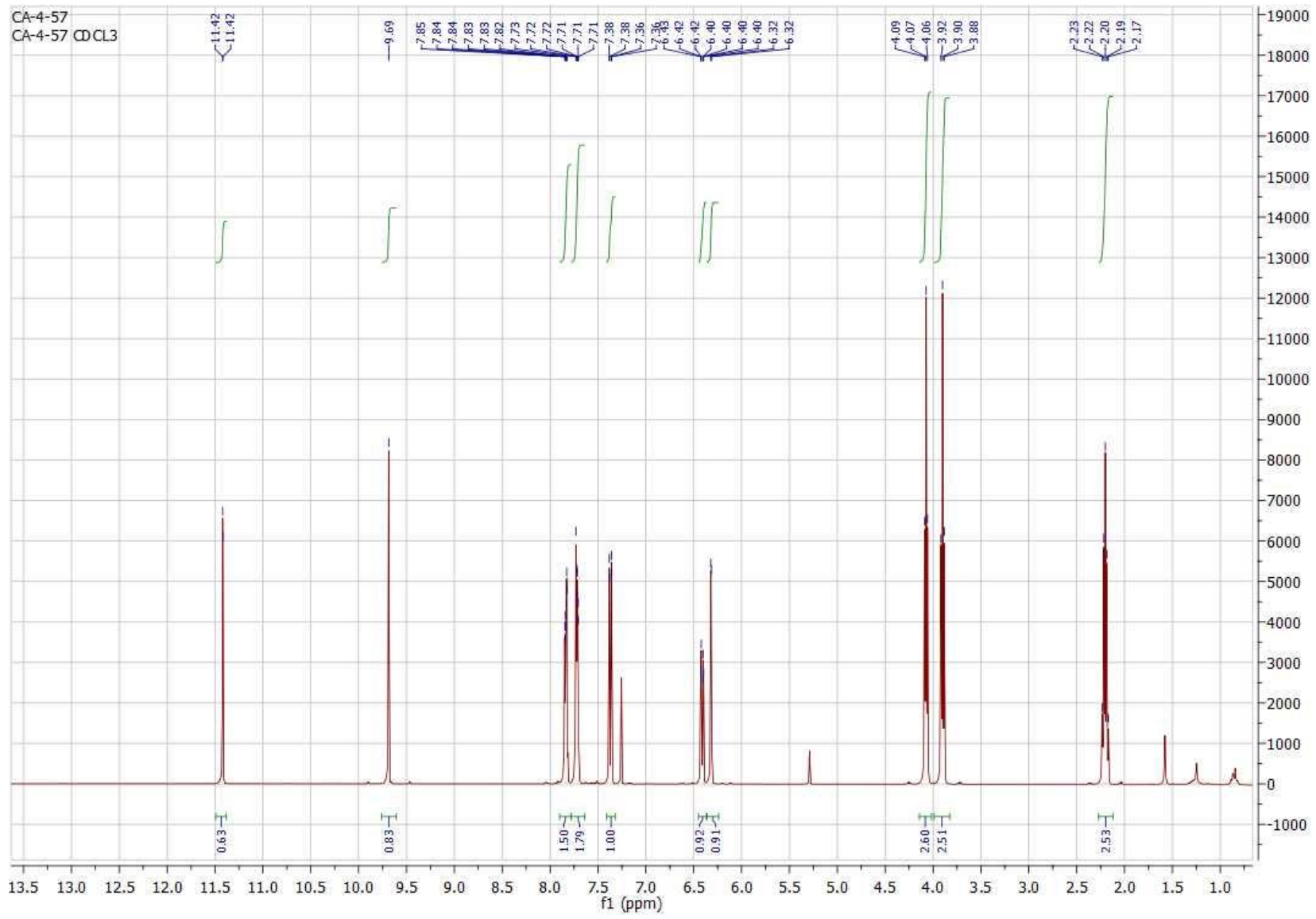


${ }^{13} \mathrm{CNMR} \mathrm{CDCl}_{3}$

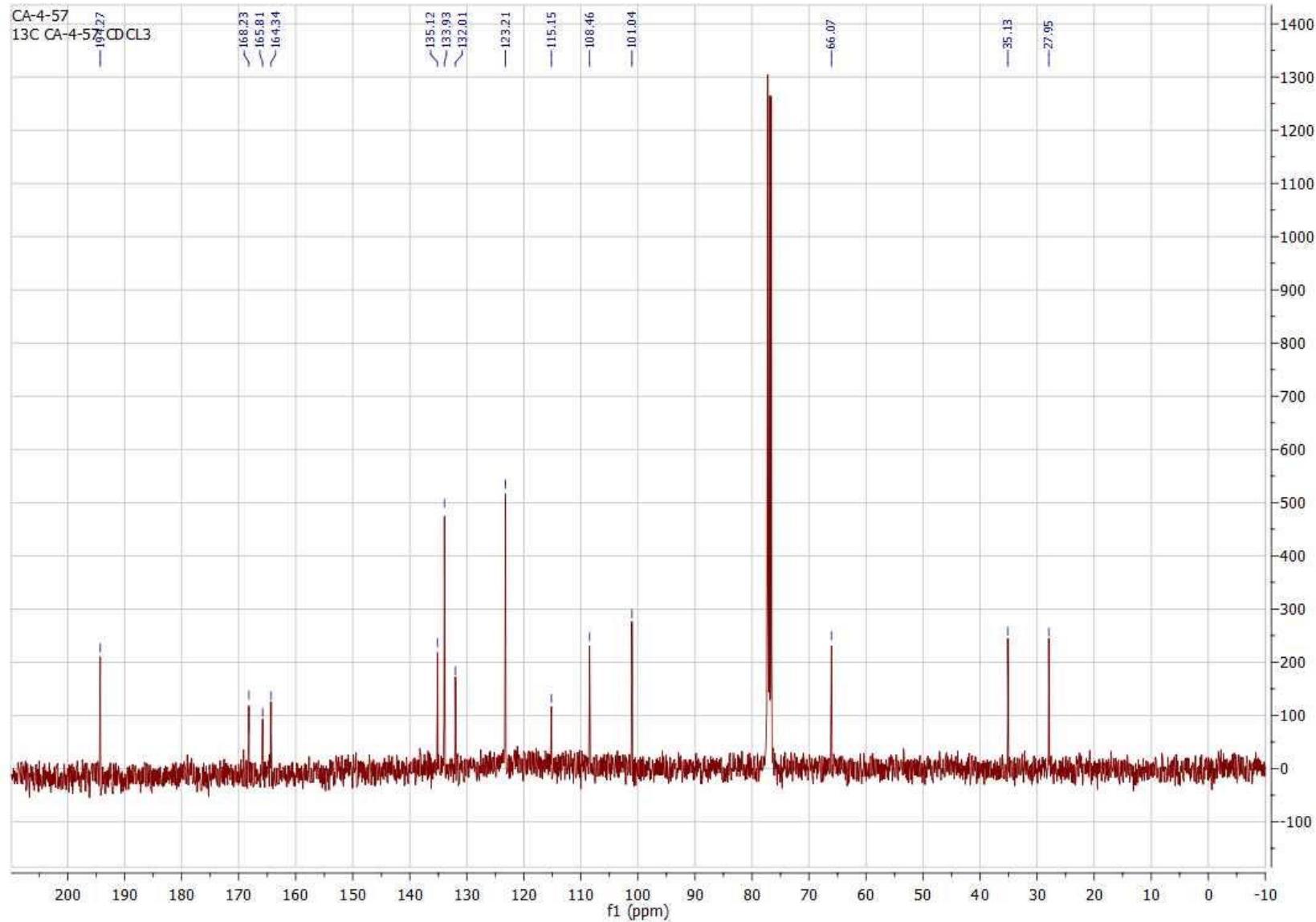


Compound 13, ${ }^{1} \mathrm{HNMR} \mathrm{CDCl}_{3}$
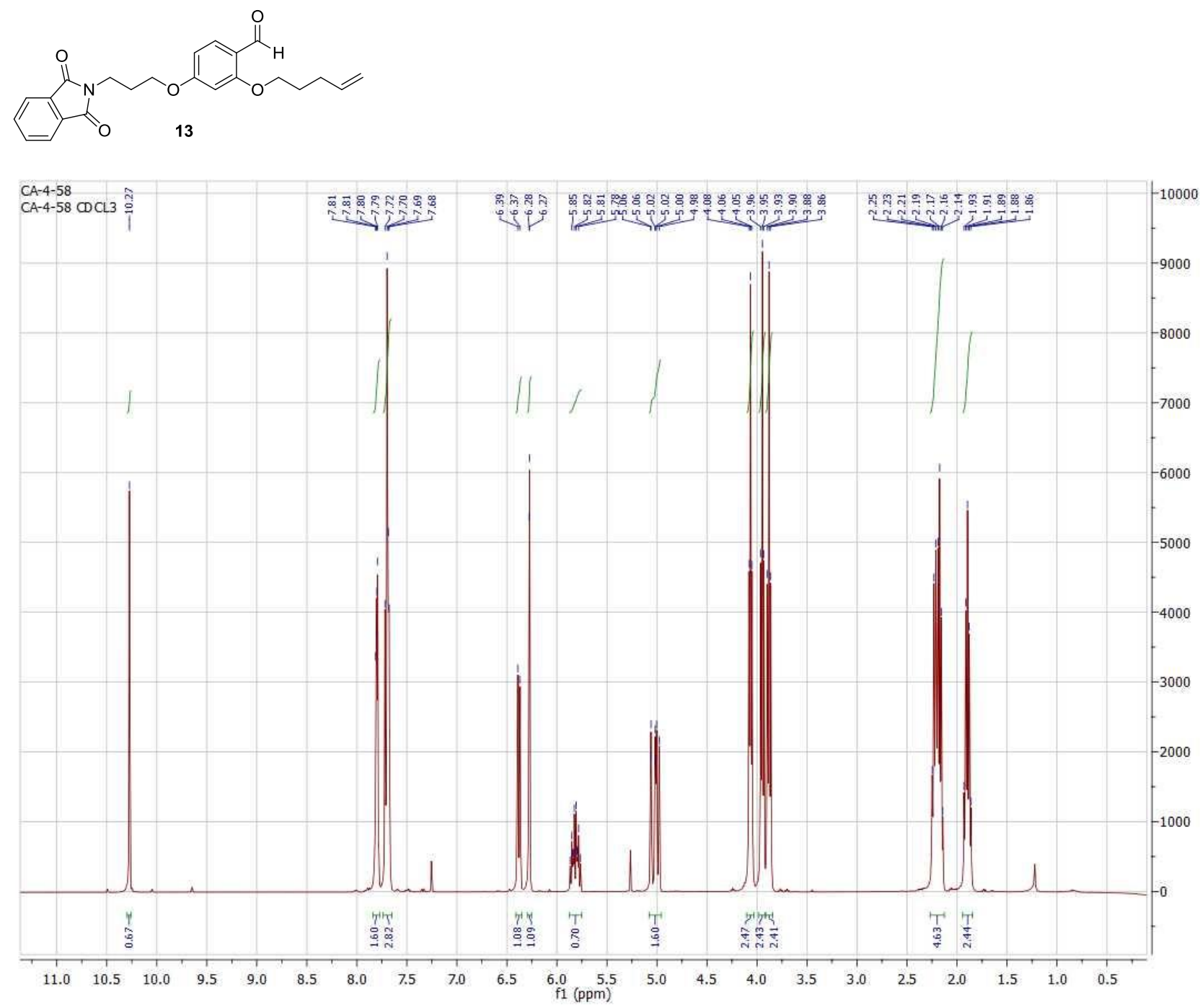
${ }^{13} \mathrm{CNMR} \mathrm{CDCl}_{3}$

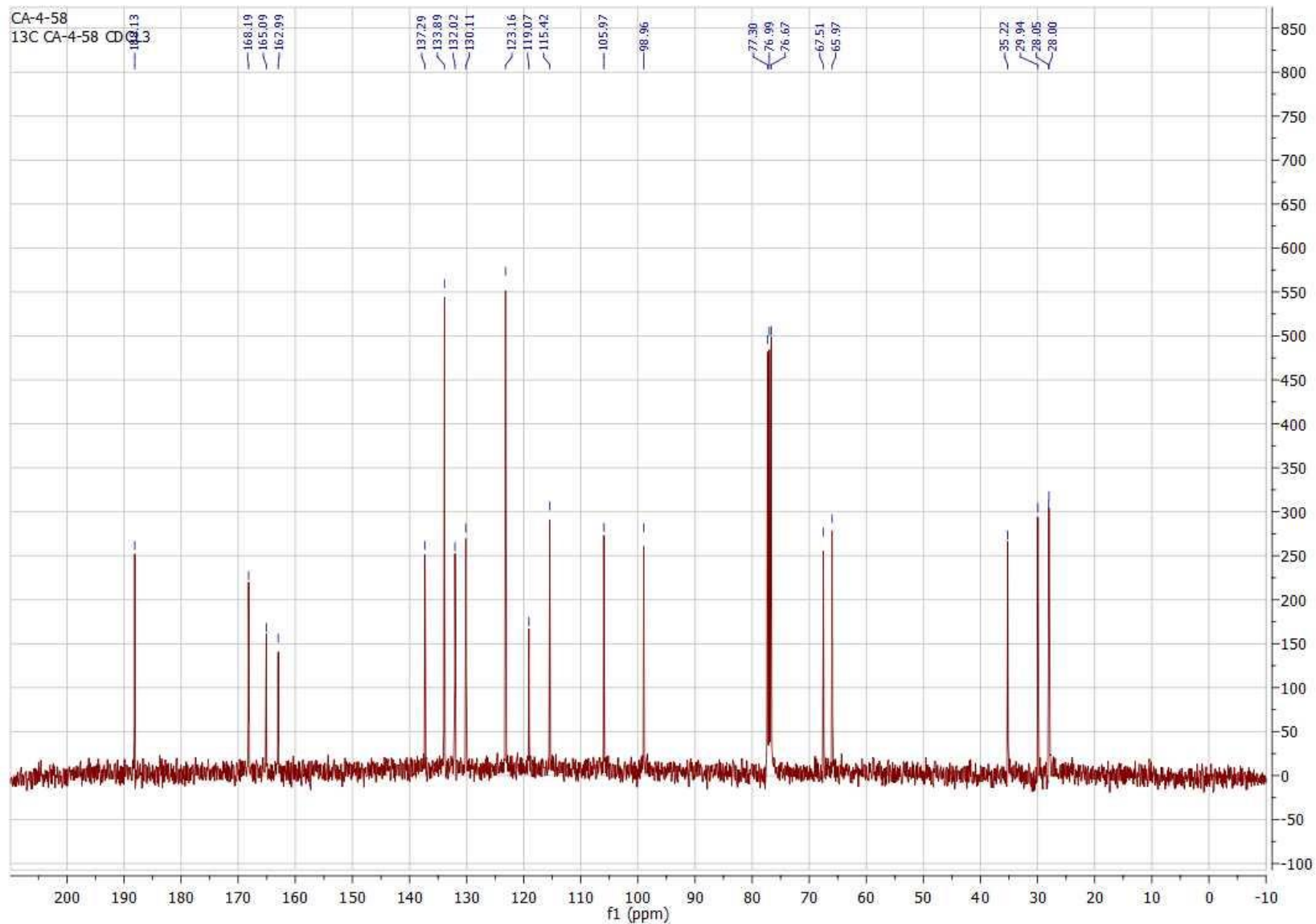


Compound 14, ${ }^{1} \mathrm{HNMR} \mathrm{CDCl}_{3}$<smiles>C=CCCCOc1cc(OCCCN2C(=O)c3ccccc3C2=O)ccc1C=NO</smiles>

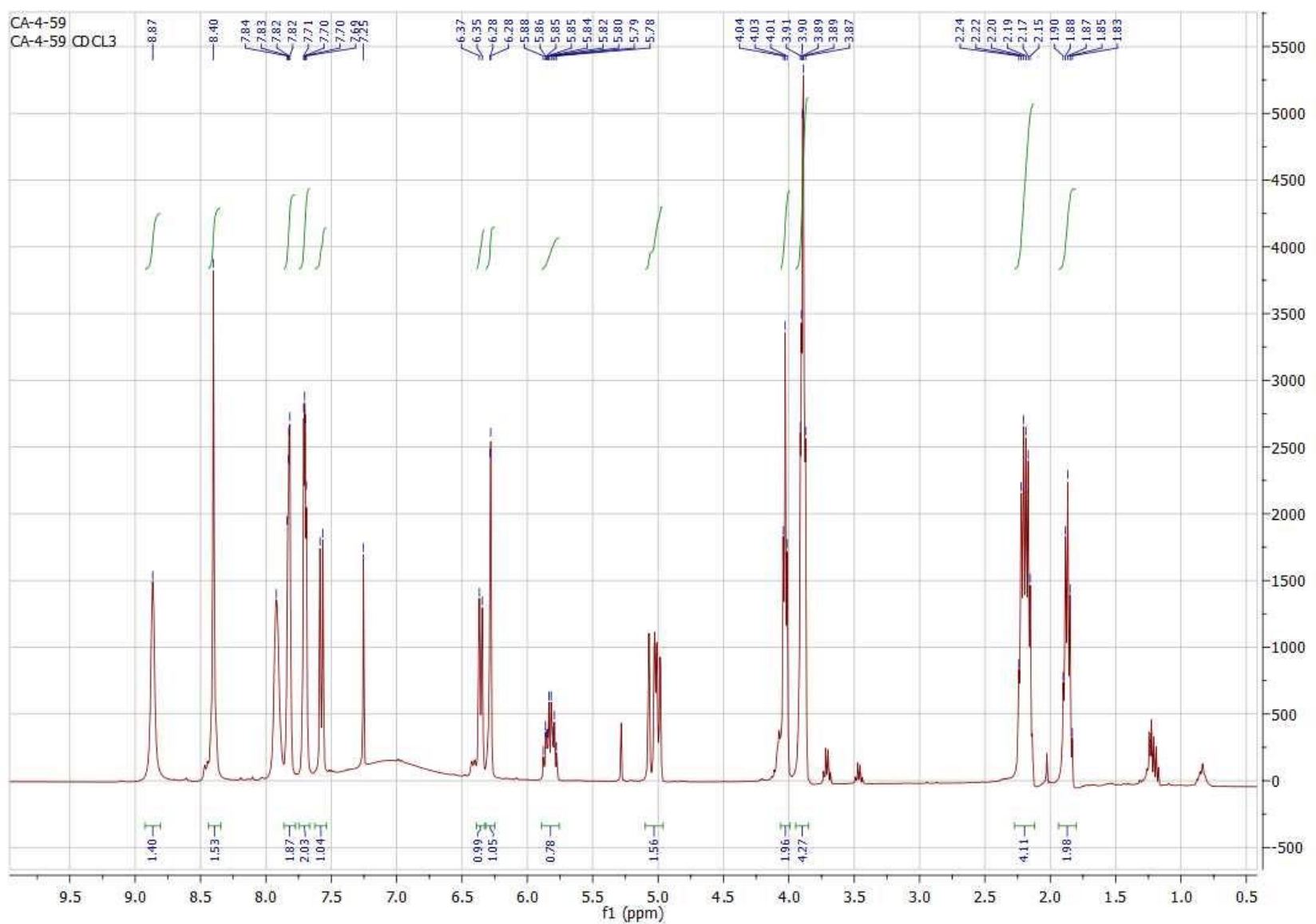


${ }^{13} \mathrm{CNMR} \mathrm{CDCl}_{3}$

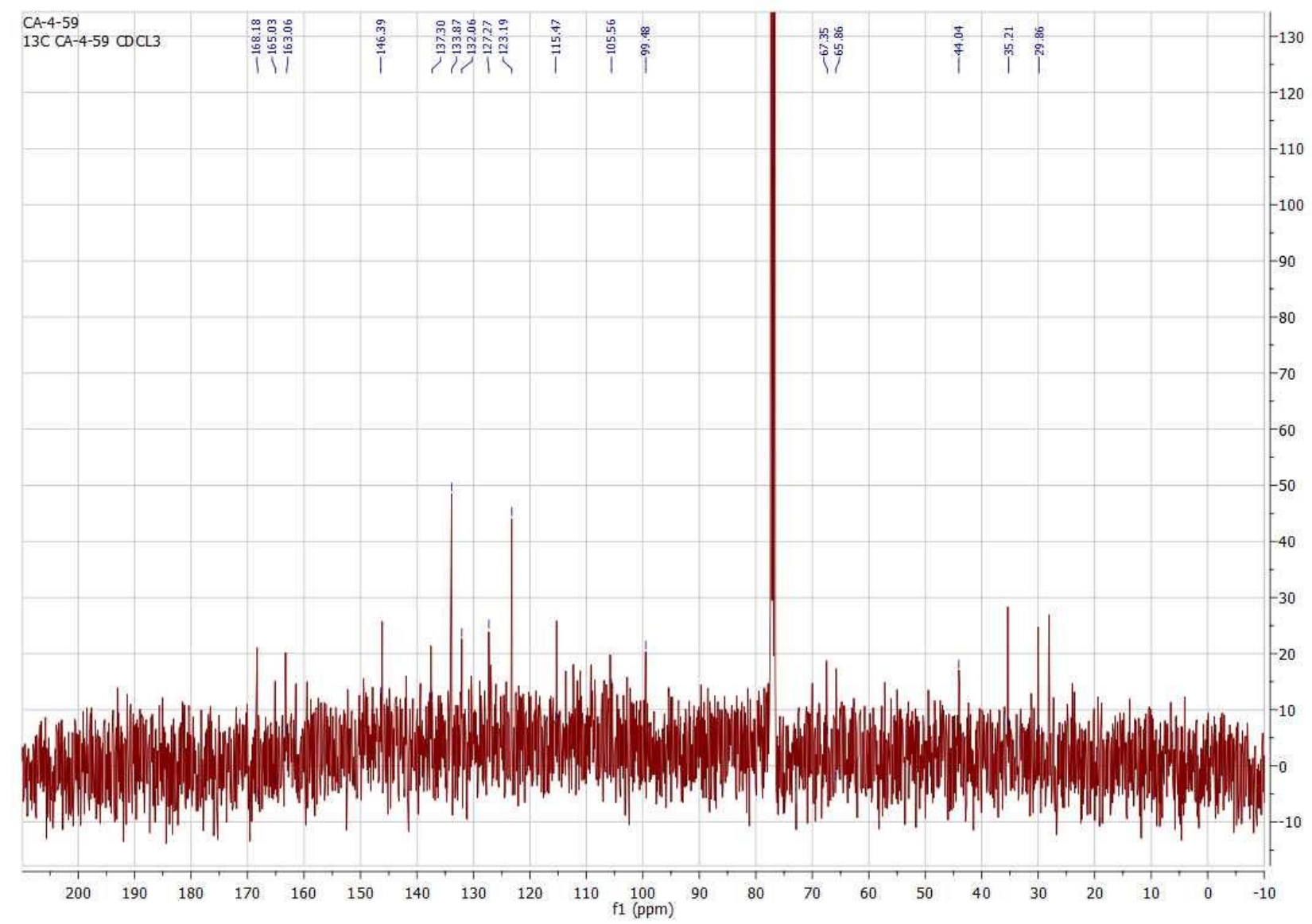


Compound 15, ${ }^{1} \mathrm{HNMR} \mathrm{CDCL}_{3}$

(15)

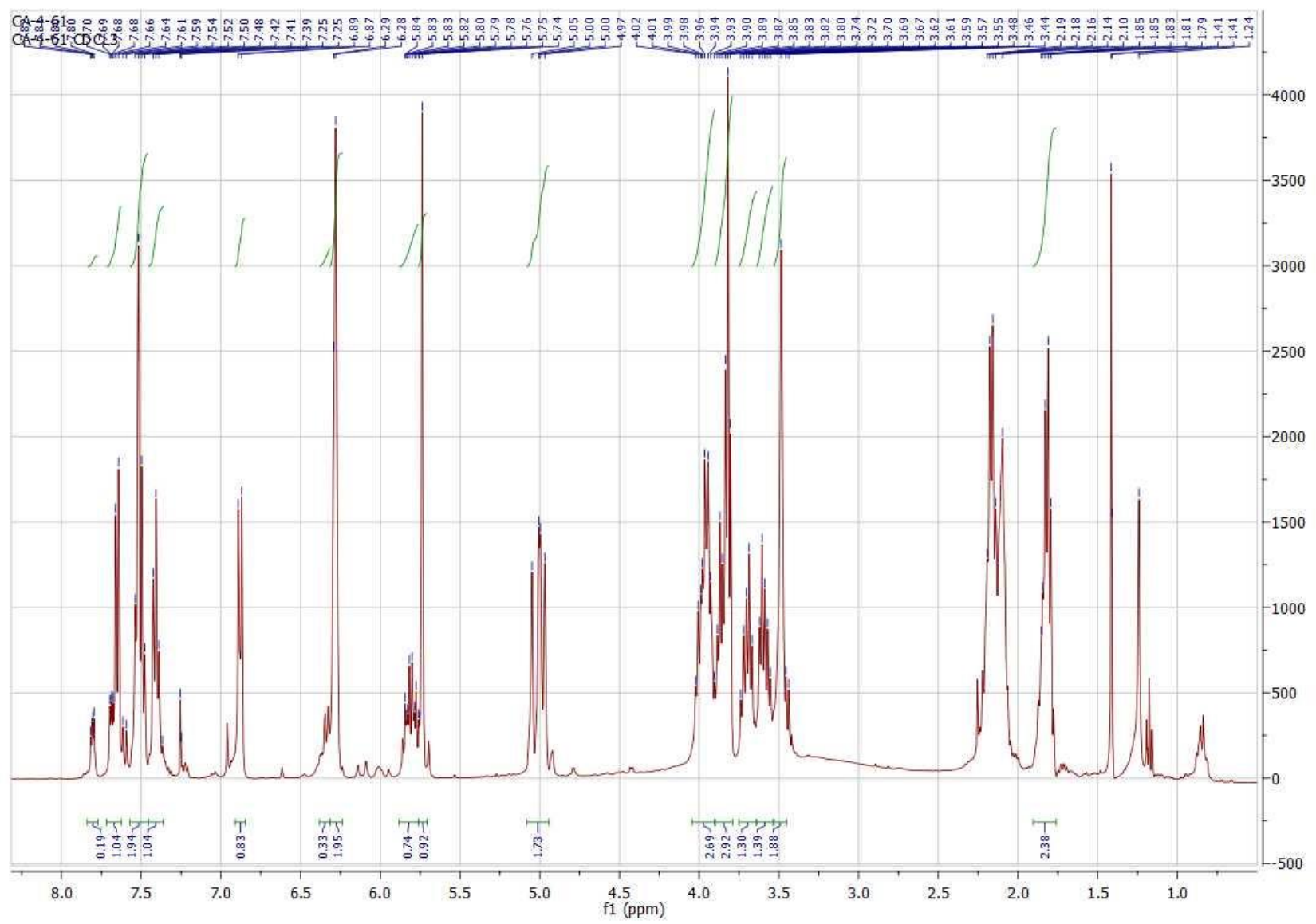


Compound 16, ${ }^{1} \mathrm{HNMR} \mathrm{CDCl}_{3}$<smiles>C=CCCCOc1cc(OCCCN2C(=O)c3ccccc3C2O)ccc1CNC(=NC(=O)c1ccccc1)NC(=O)c1ccccc1</smiles>

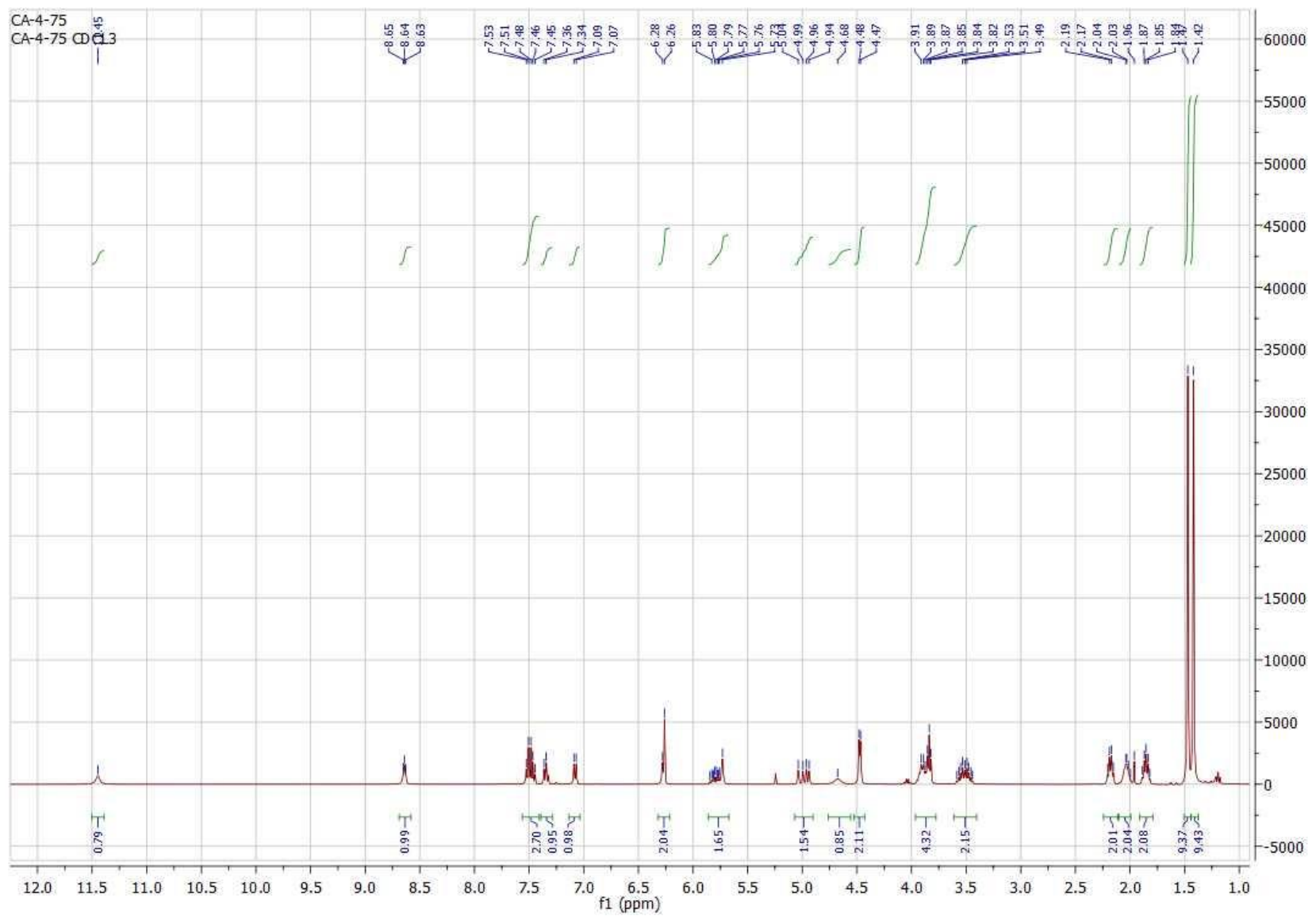


${ }^{13} \mathrm{CNMR} \mathrm{CDCl}_{3}$

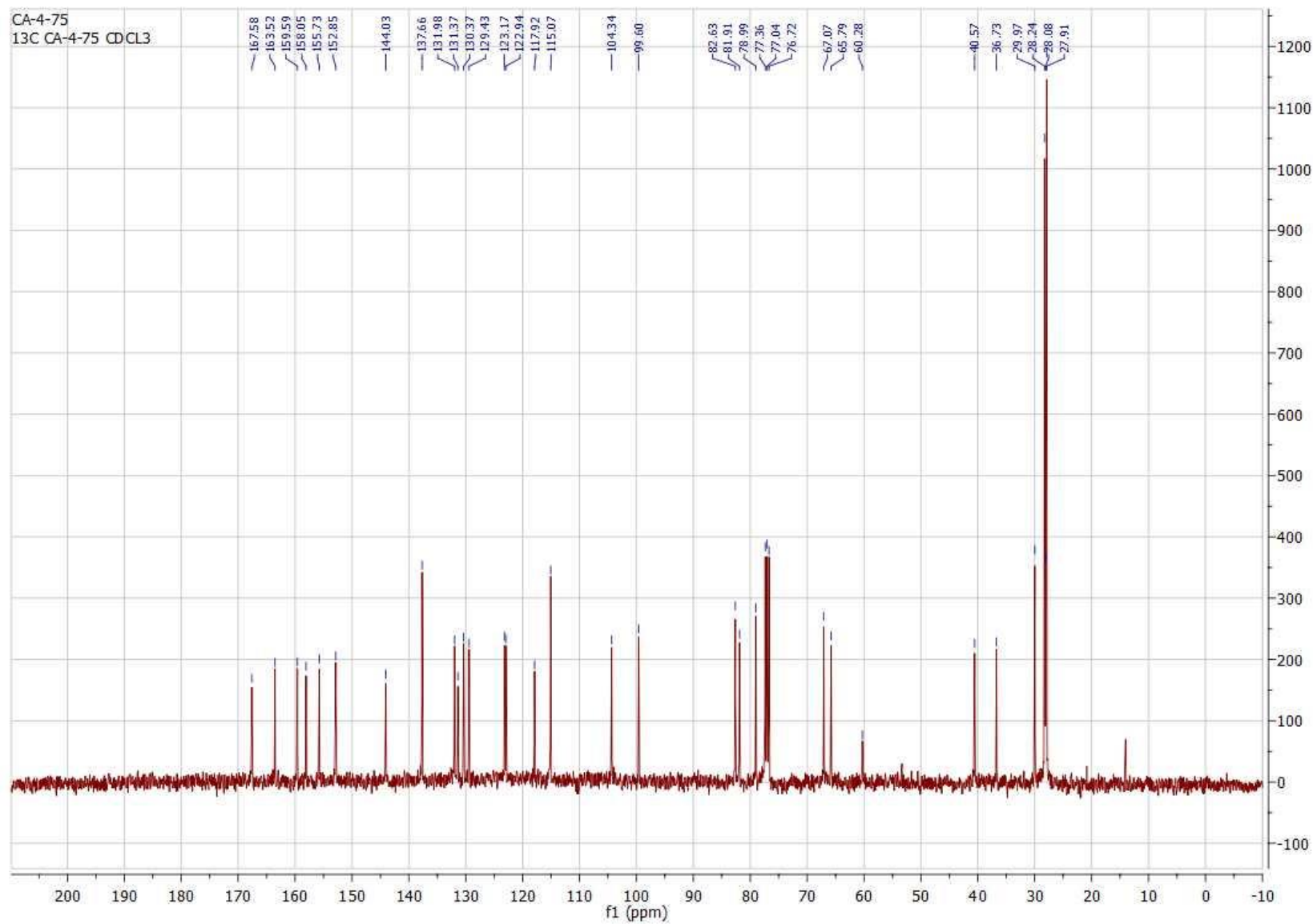


Compound 18, ${ }^{1} \mathrm{HNMR} \mathrm{CDCL}_{3}$<smiles>C=CCCCOc1ccccc1CNC(=NC(=O)c1ccccc1)NC(=O)N(CC=C)CCCCCCCCNCCCCN1C(=O)c2ccccc2C1O</smiles>

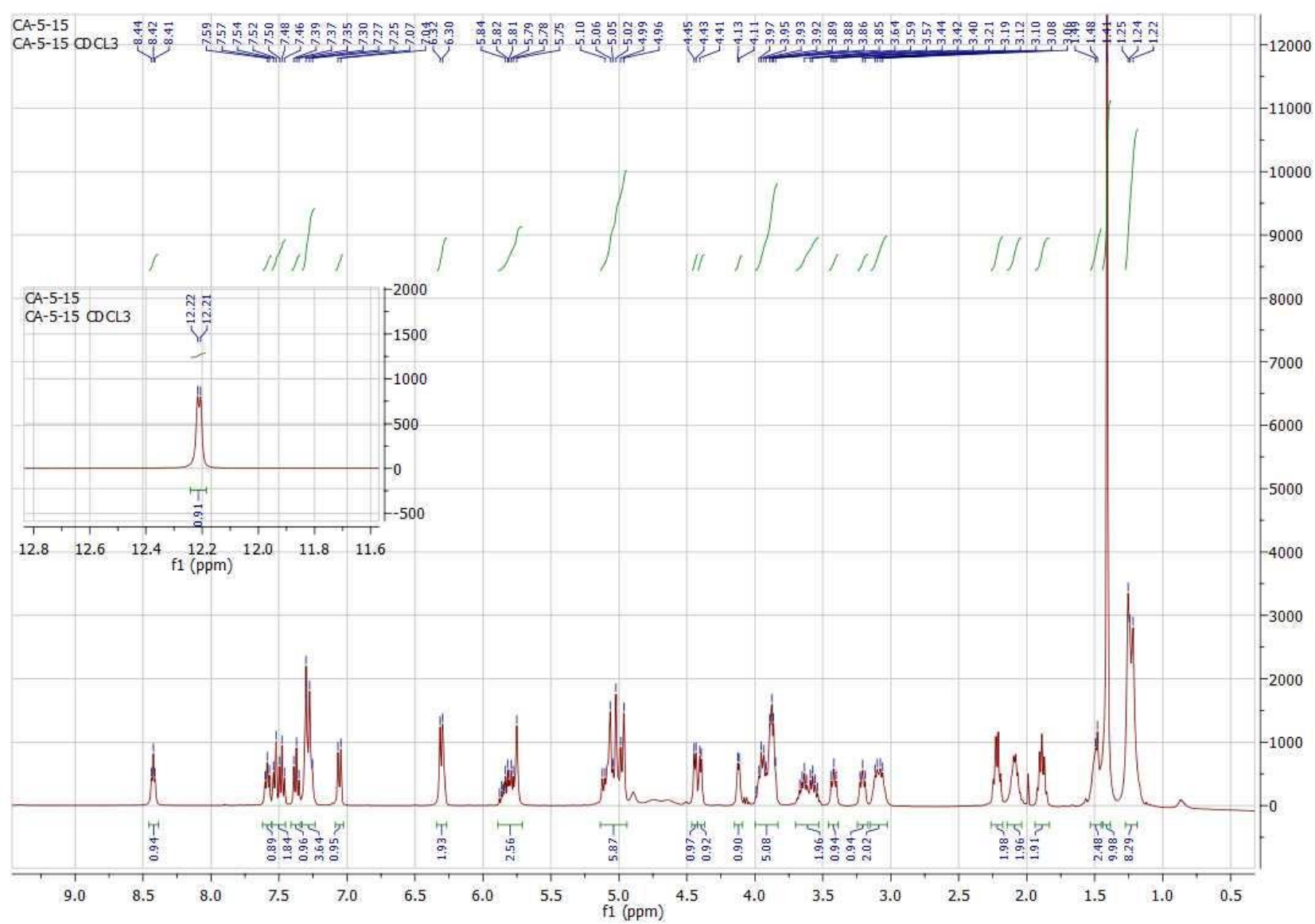


${ }^{13} \mathrm{CNMR} \mathrm{CDCl}_{3}$

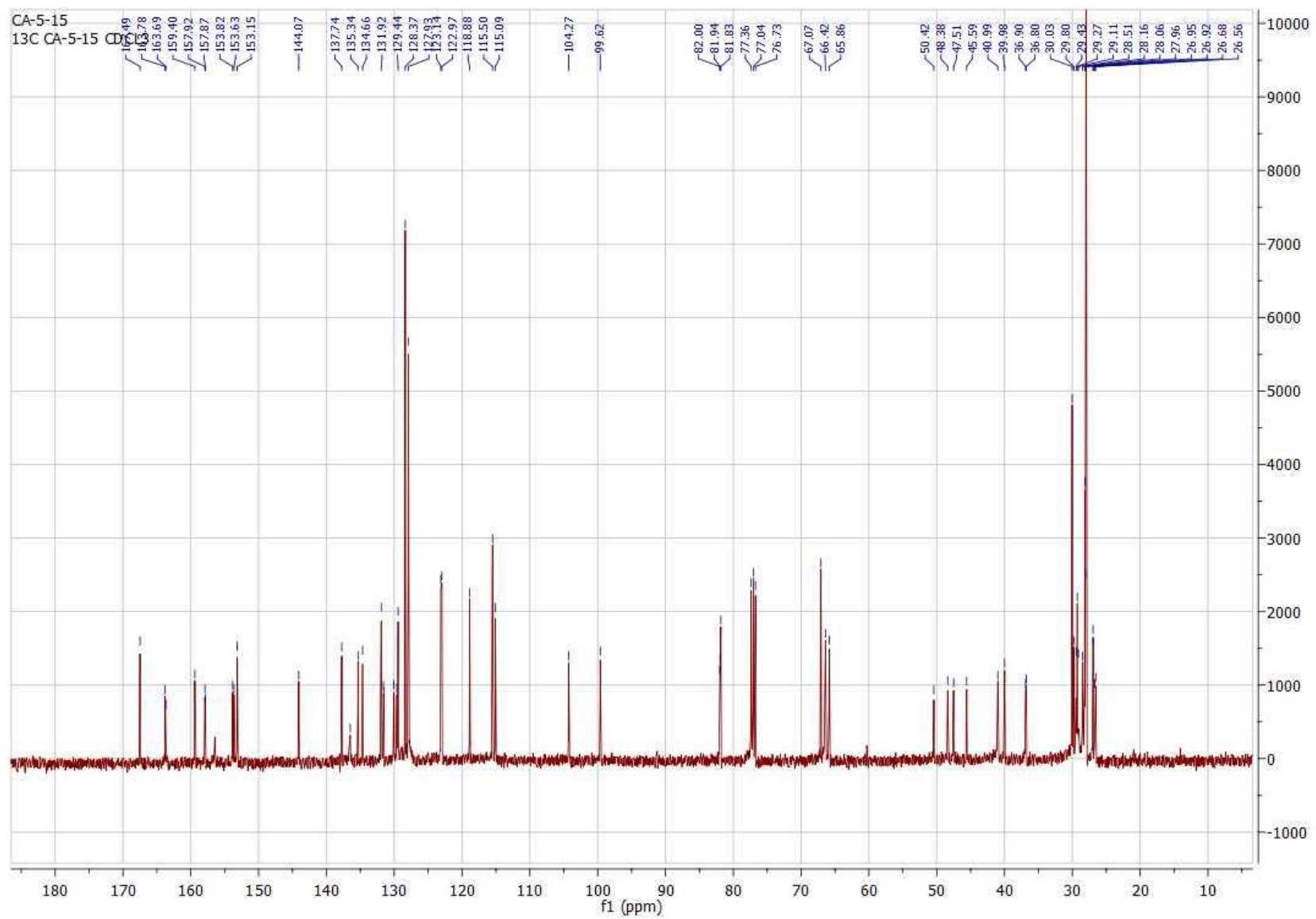


Compound 19, ${ }^{1} \mathrm{HNMR} \mathrm{CDCl}_{3}$

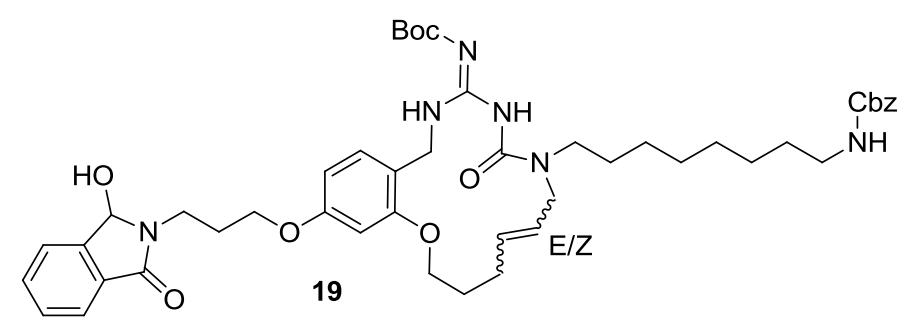

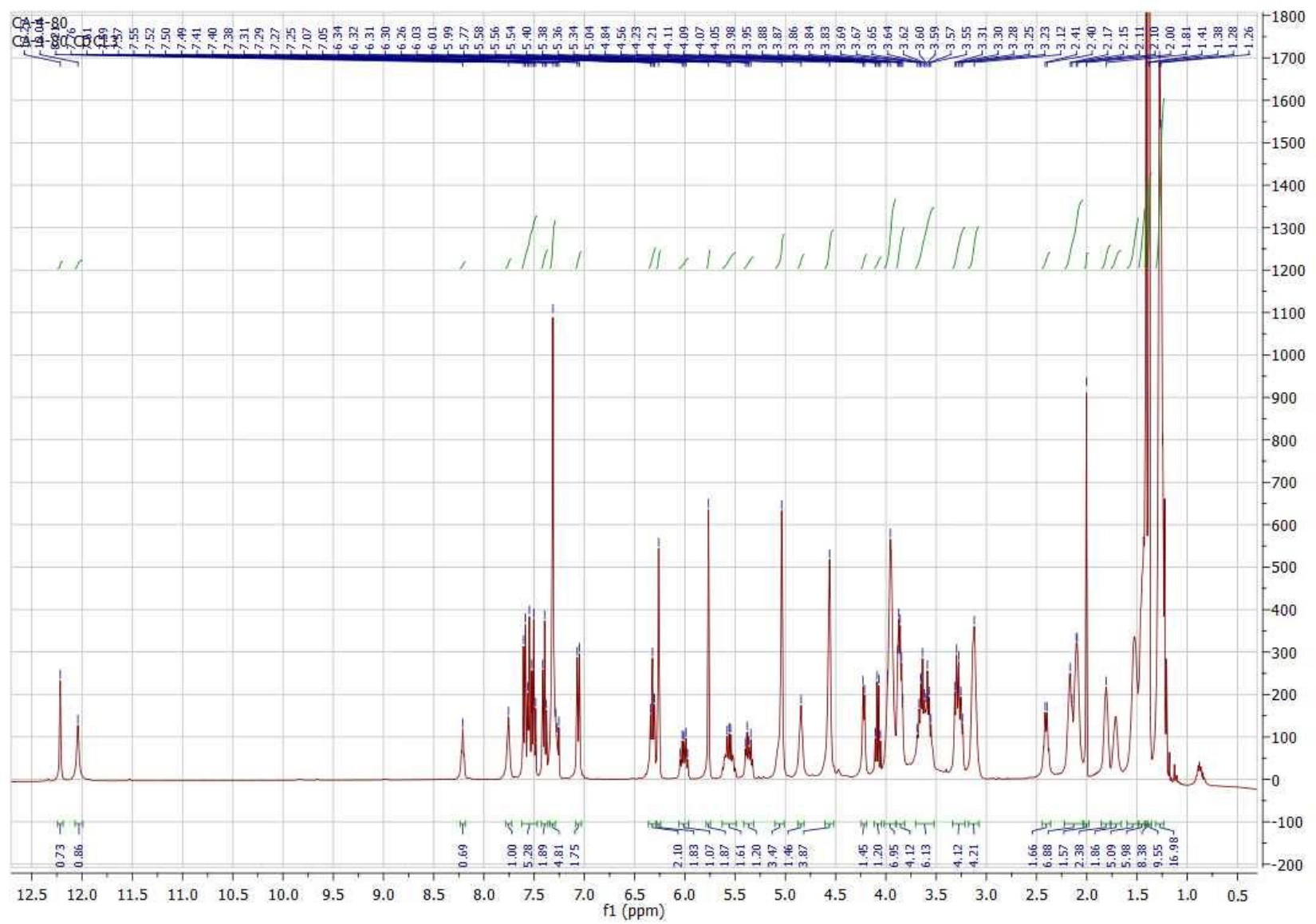


${ }^{13} \mathrm{CNMR} \mathrm{CDCl}_{3}$

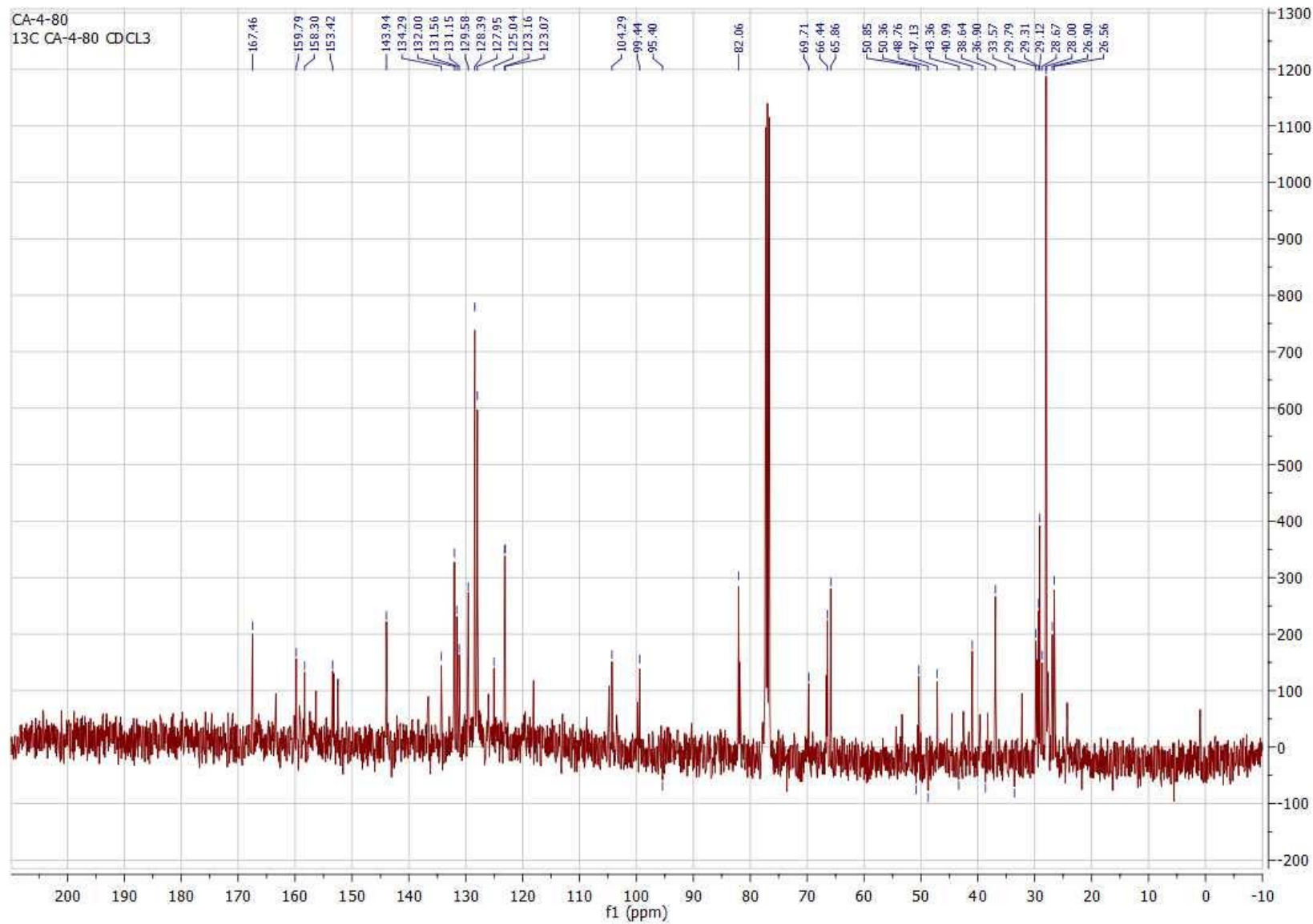



yl)propoxy)-2,3,4,5,8,9,10,11,12,15-decahydrobenzo[b] $[1,5,7,9]$ oxatriazacycloheptadecin-13yl)carbamate, ${ }^{1} \mathrm{HNMR} \mathrm{CDCl}_{3}$<smiles>[Z2]CCCCN(CCCCCCCCNC(=O)c1ccccc1)C(=O)NC(=NC(=O)c1ccccc1)NCc1ccc(OCCCN2C(=O)c3ccccc3C2=O)cc1OCCCCCCC(=O)c1ccccc1</smiles>

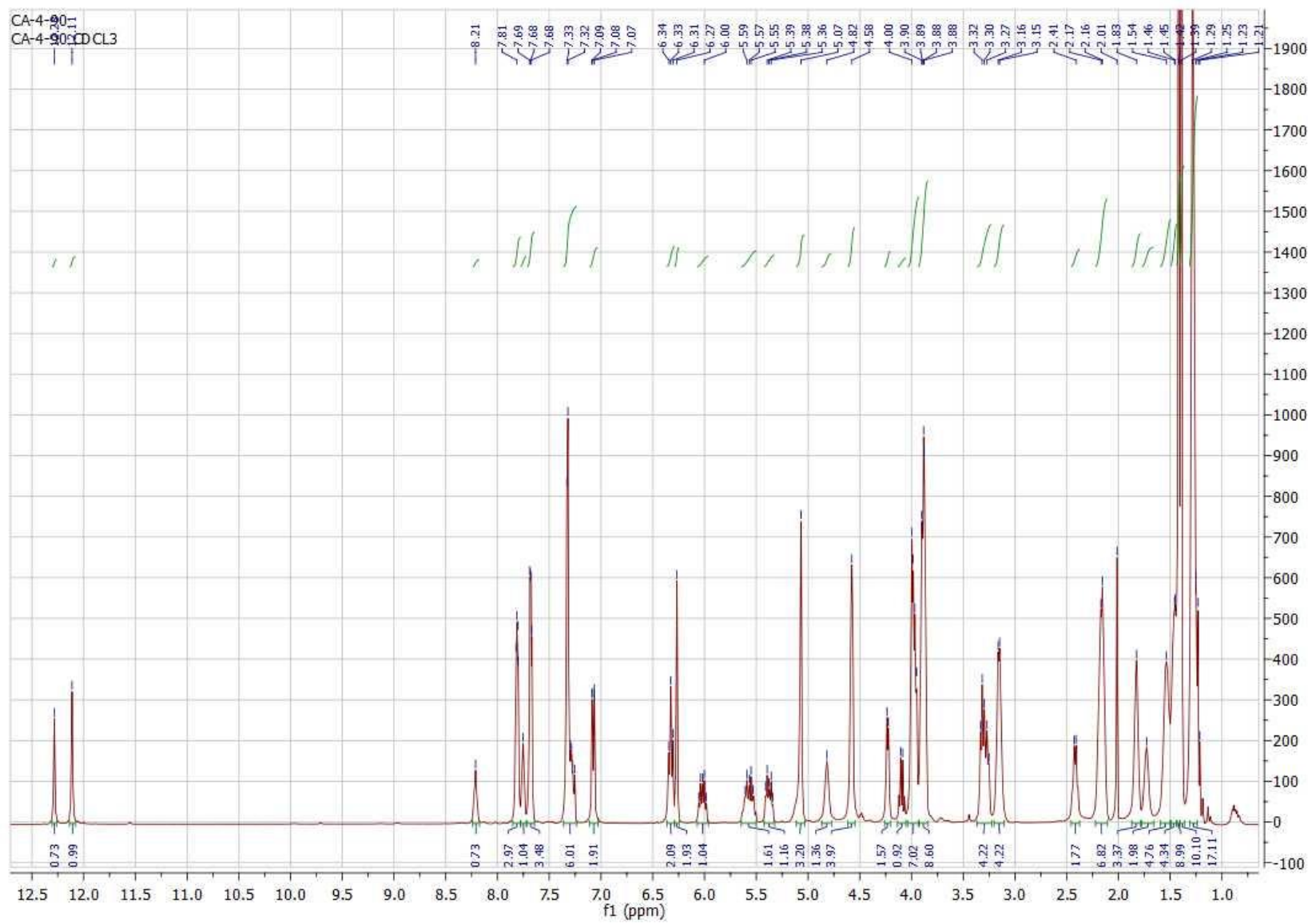


${ }^{13} \mathrm{CNMR} \mathrm{CDCl}_{3}$

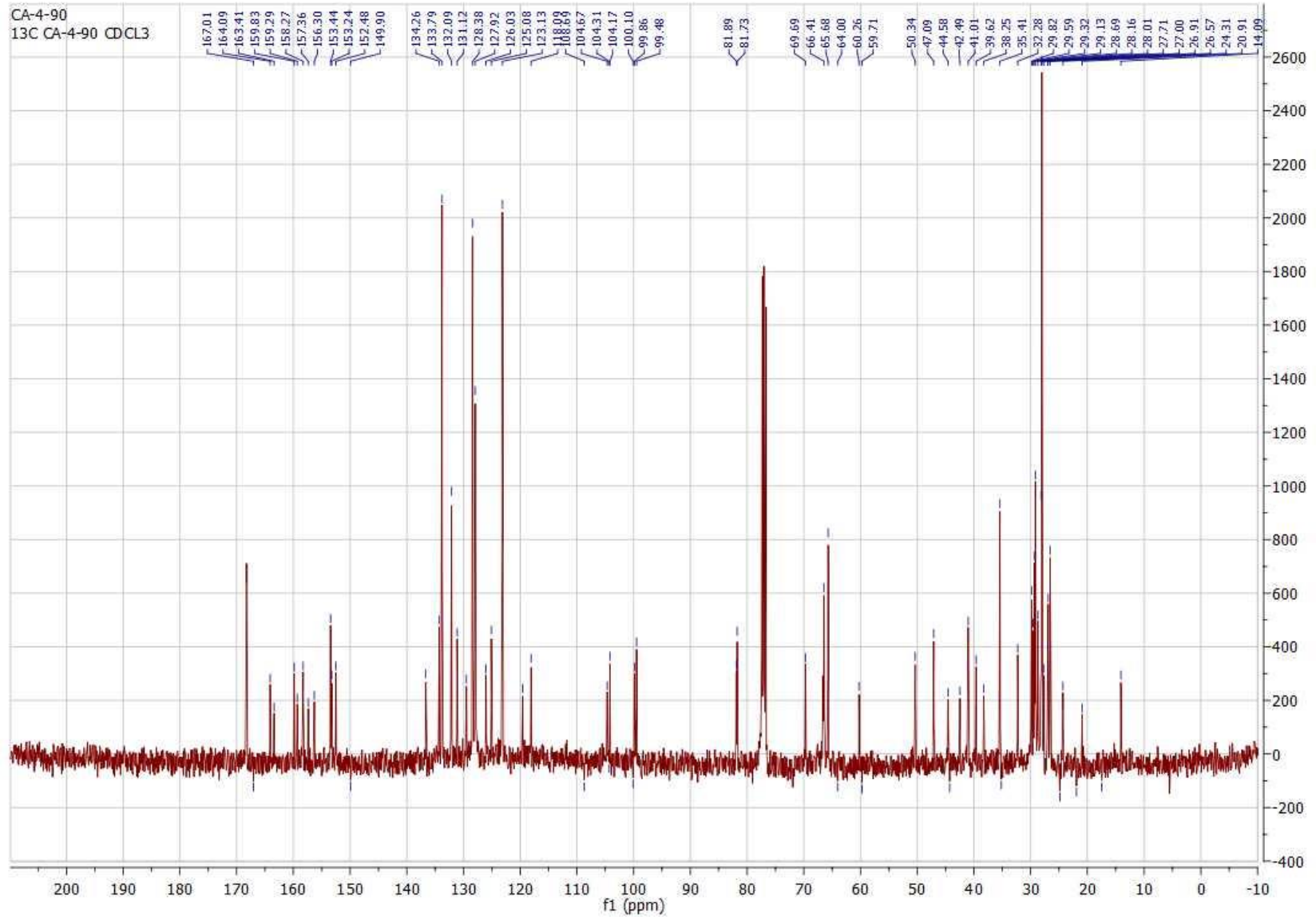


Compound 20, ${ }^{1} \mathrm{HNMR} \mathrm{CDCL}_{3}$

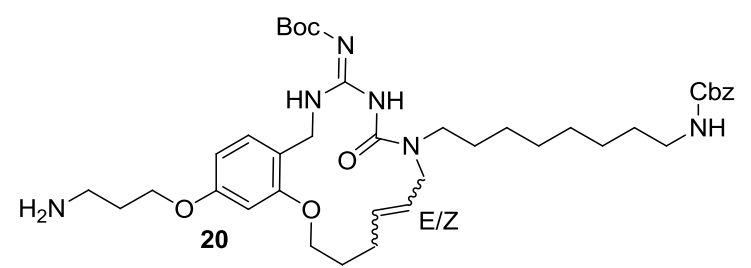

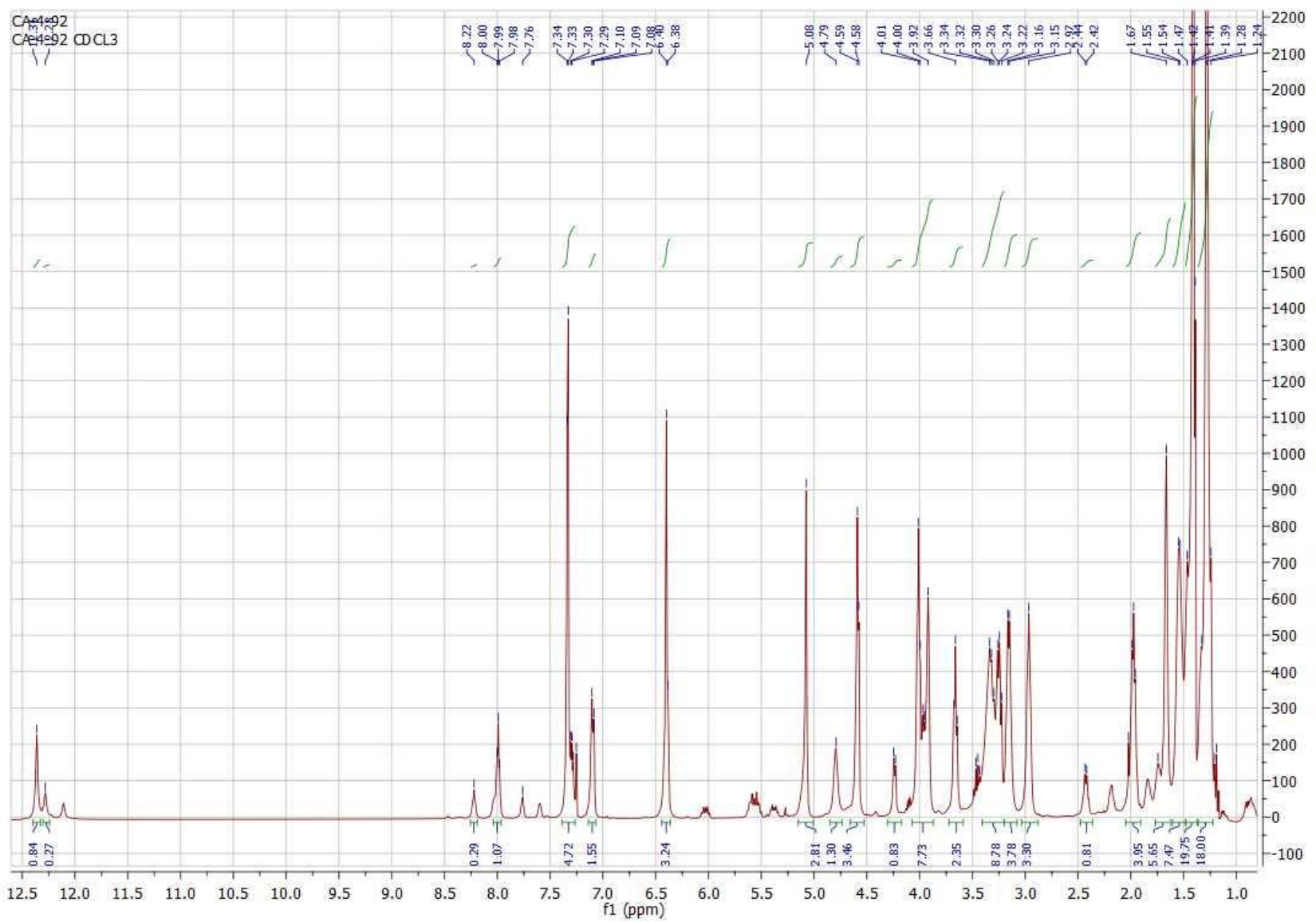


${ }^{13} \mathrm{CNMR} \mathrm{CDCl}_{3}$

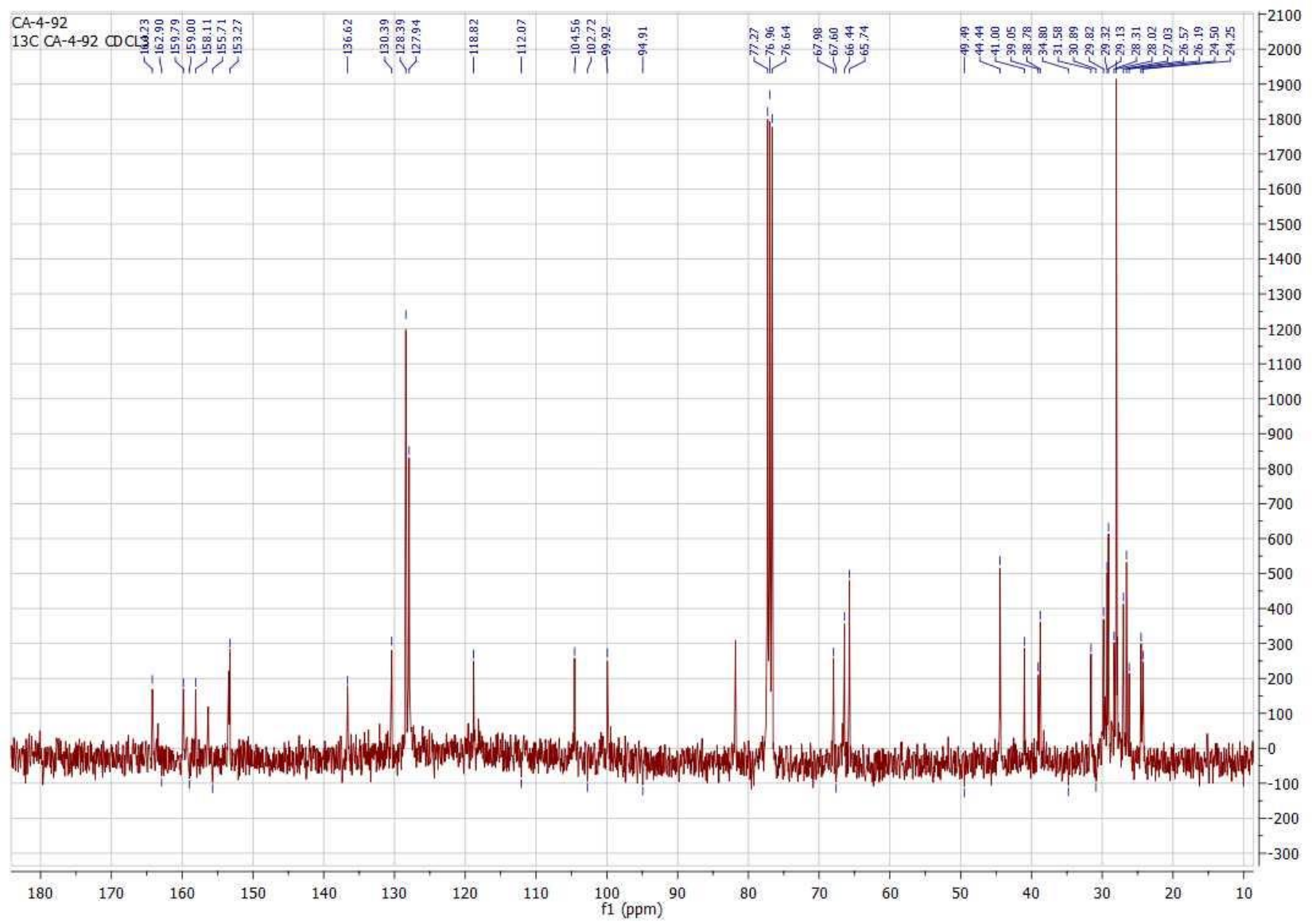


Compound 21, ${ }^{1} \mathrm{HNMR} \mathrm{CDCl}_{3}$<smiles>[Z2]CCCOc1cc(OCCCNC(=O)C(F)(F)F)ccc1CNC(=NC(=O)c1ccccc1)NC(=O)N(CCCC)CCCCCCCCCNC(=O)OCc1ccccc1</smiles>

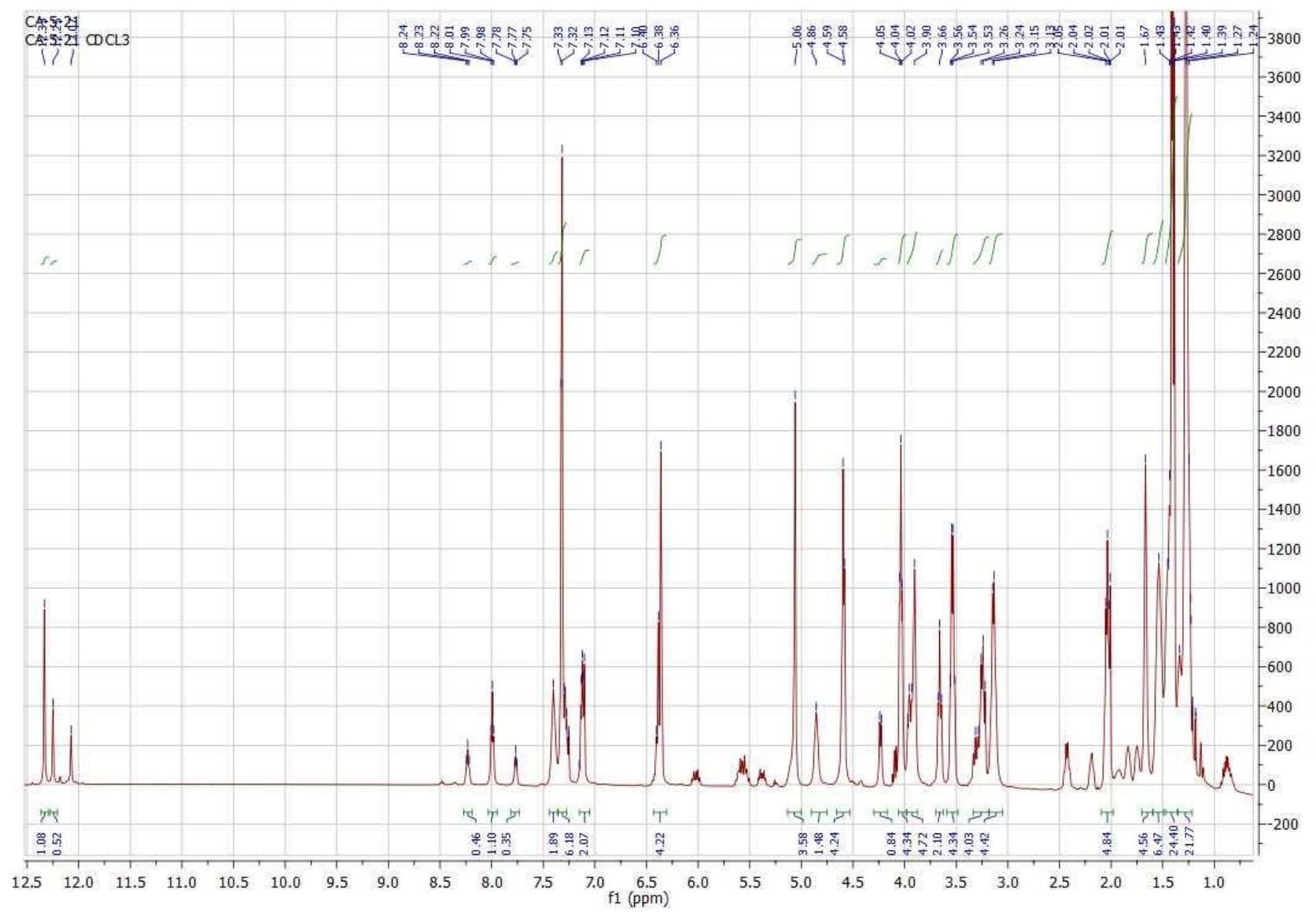


${ }^{13} \mathrm{CNMR} \mathrm{CDCl}_{3}$

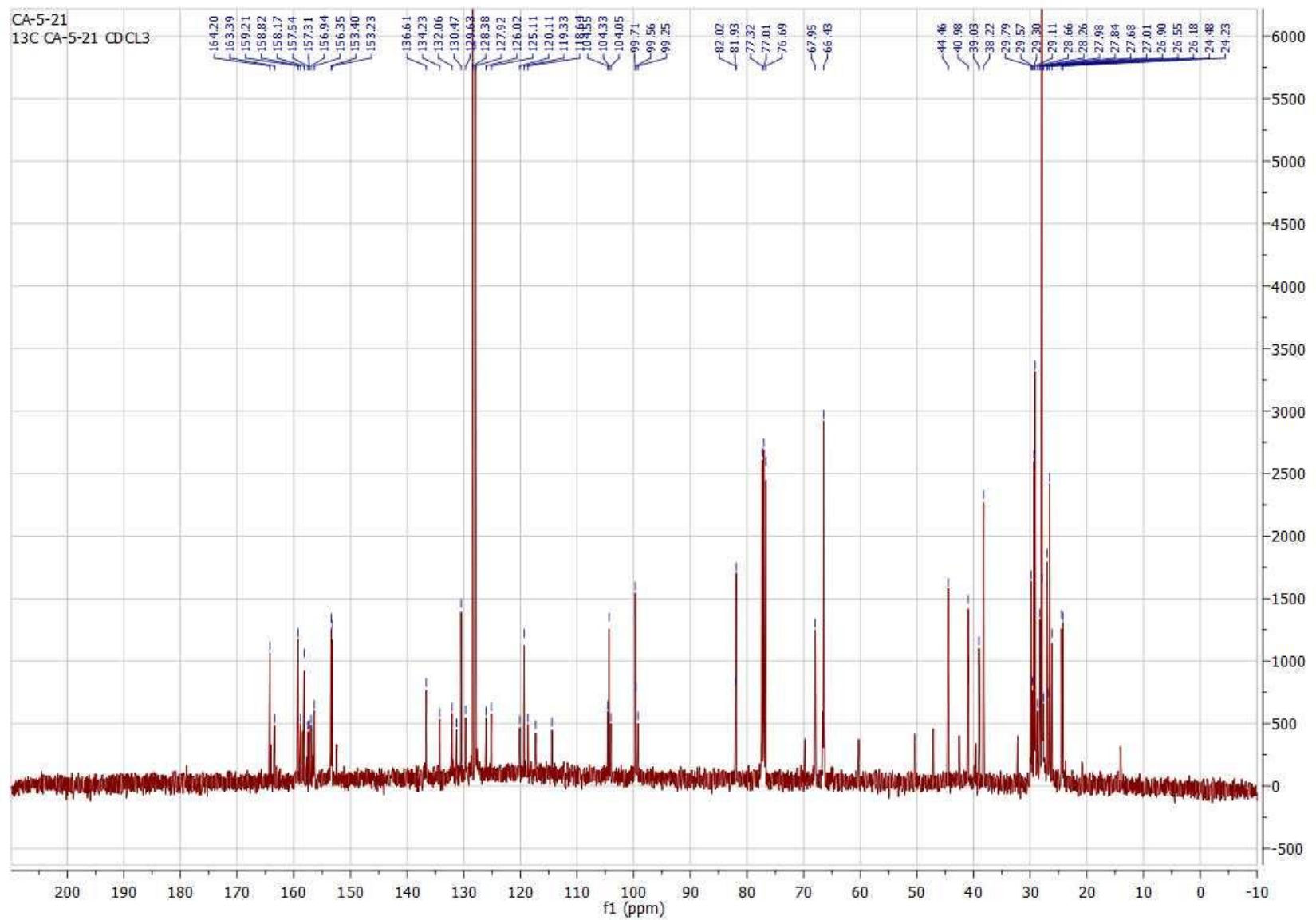


Compound 22, ${ }^{1} \mathrm{HNMR} \mathrm{CDCl}_{3} / \mathrm{MeOD}$
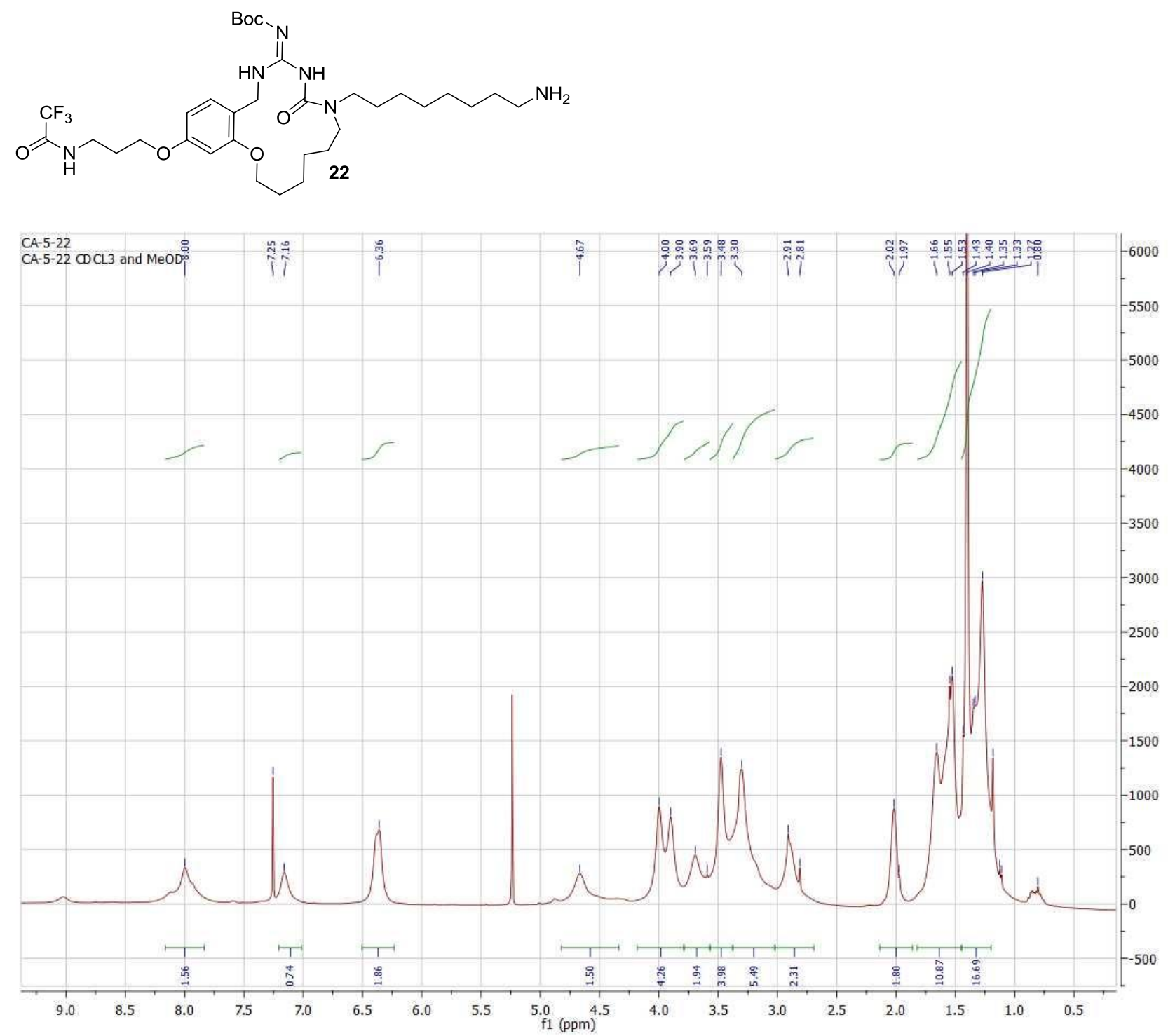
${ }^{13} \mathrm{CNMR} \mathrm{CDCl}_{3} / \mathrm{MeOD}$

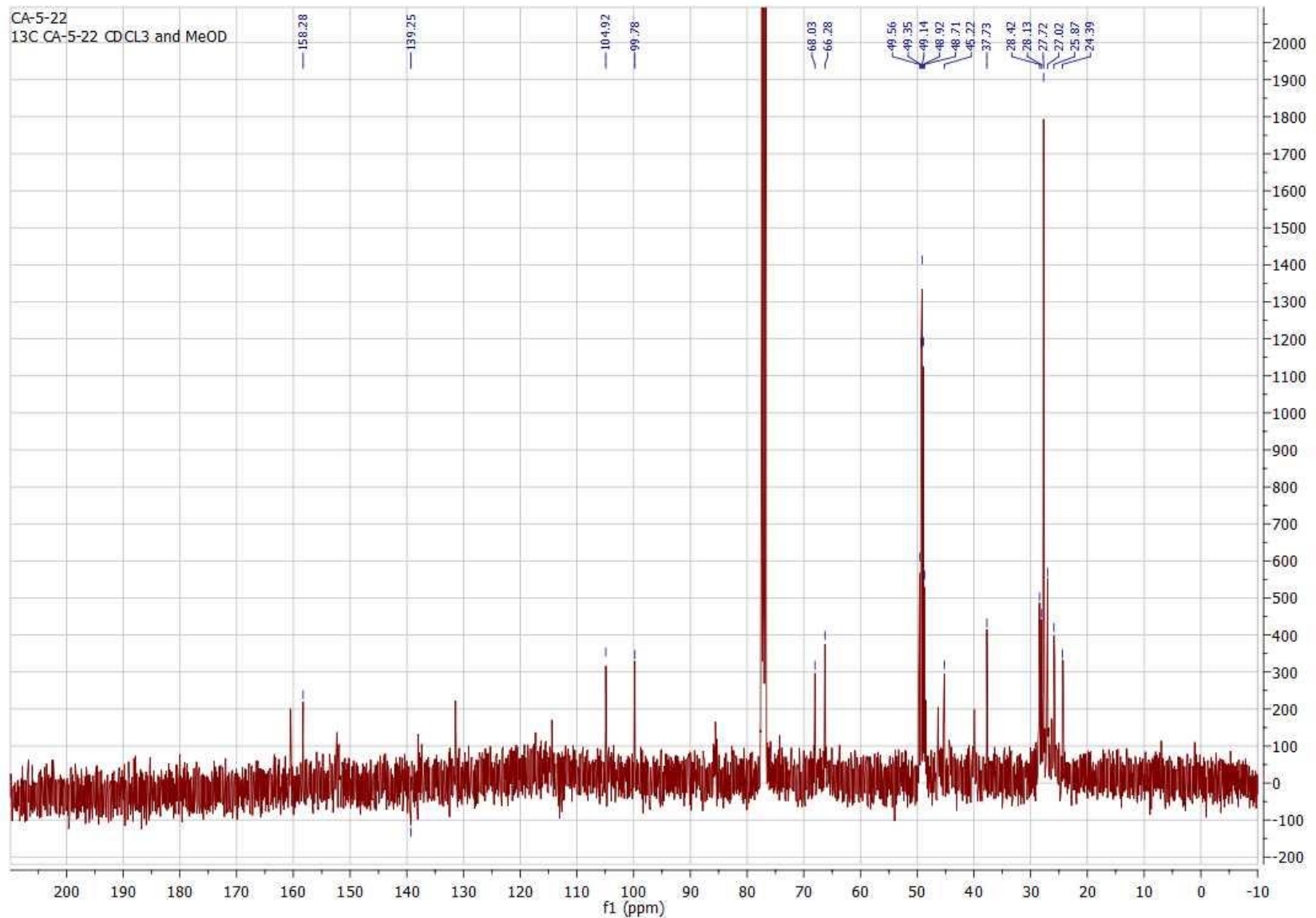


Compound 24, ${ }^{1} \mathrm{HNMR} \mathrm{CDCL}_{3}$

(c)

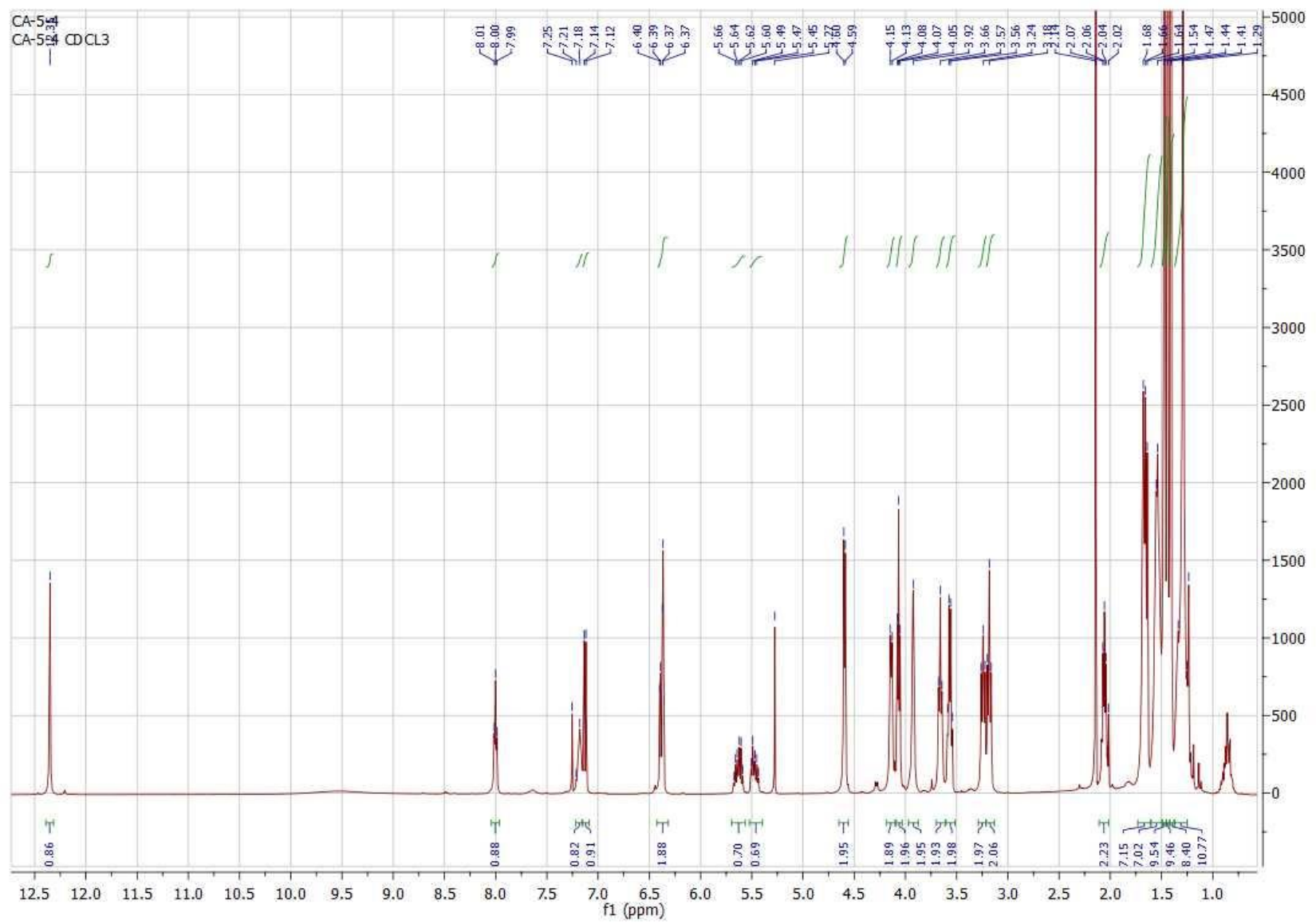


${ }^{13} \mathrm{CNMR} \mathrm{CDCl}_{3}$

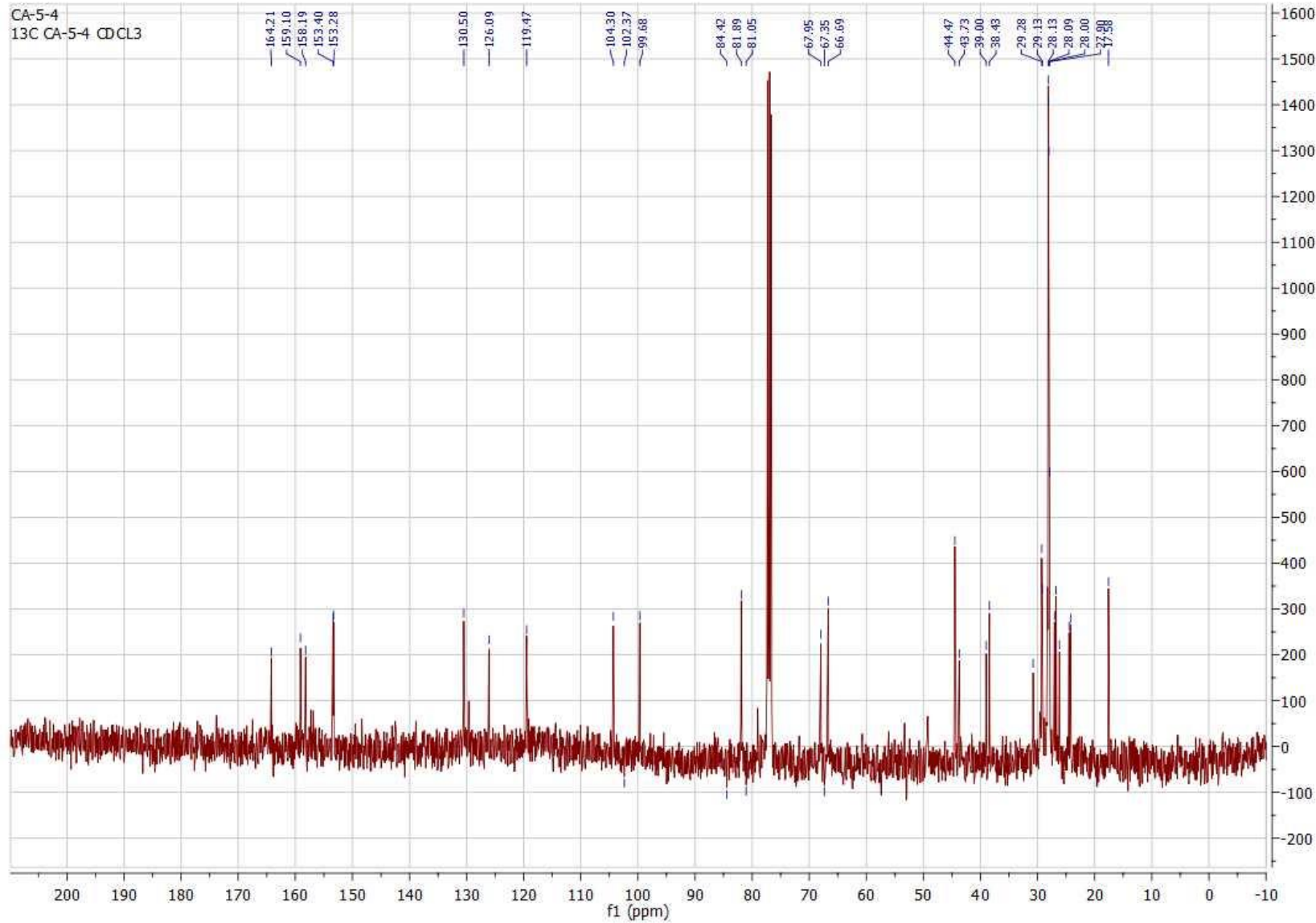


Compound 25, ${ }^{1} \mathrm{HNMR} \mathrm{CDCl}_{3}$

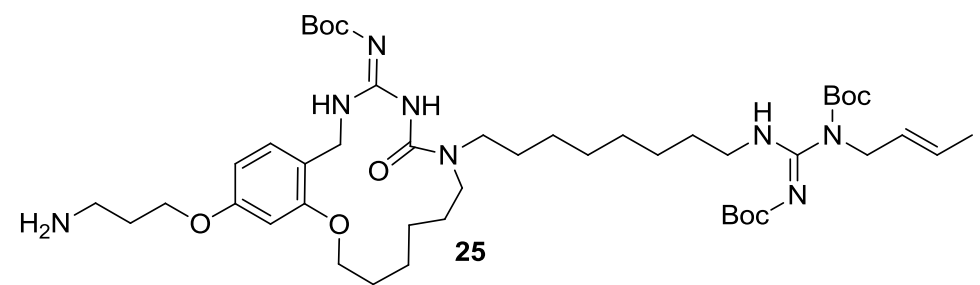

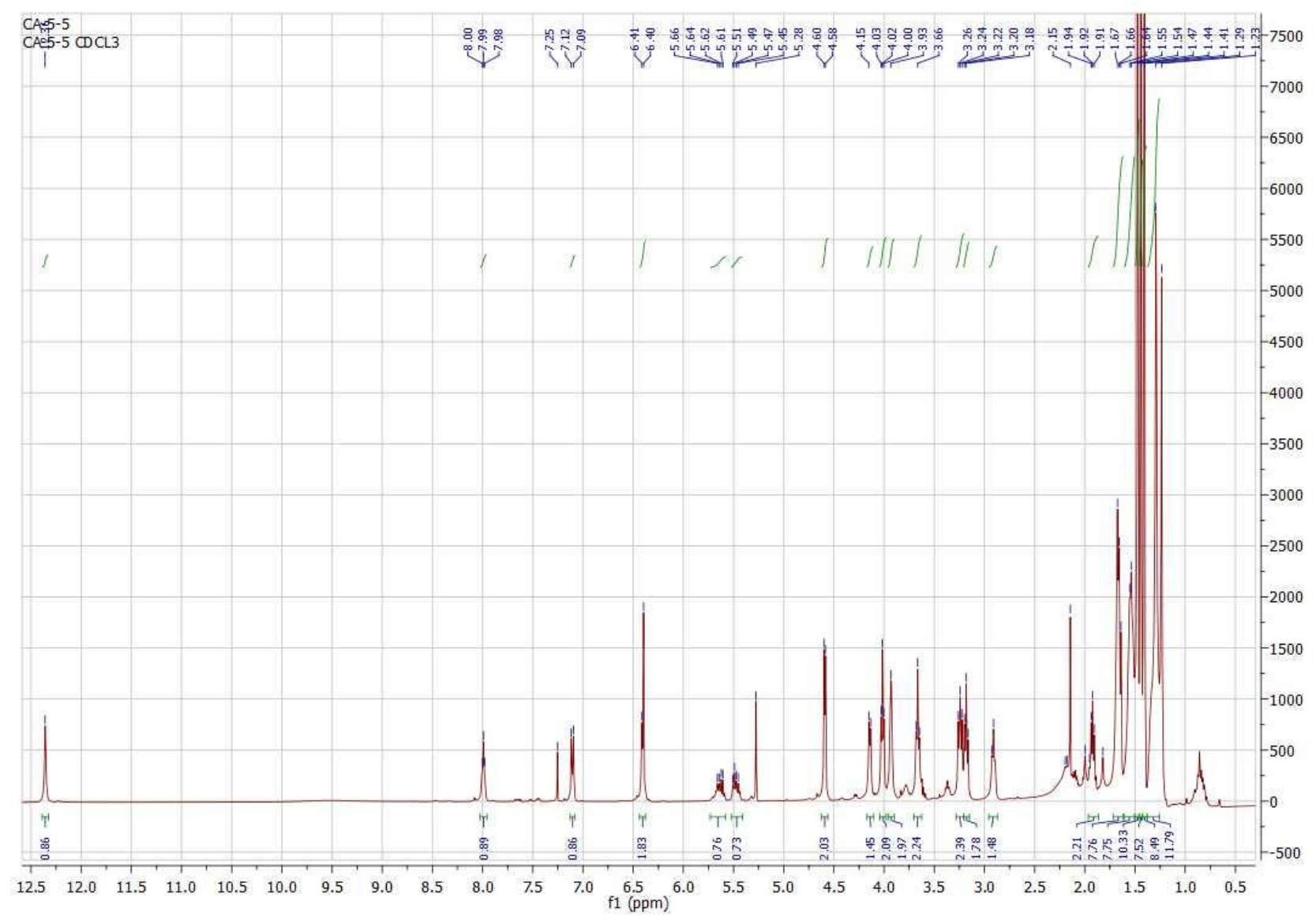


${ }^{13} \mathrm{CNMR} \mathrm{CDCl}_{3}$

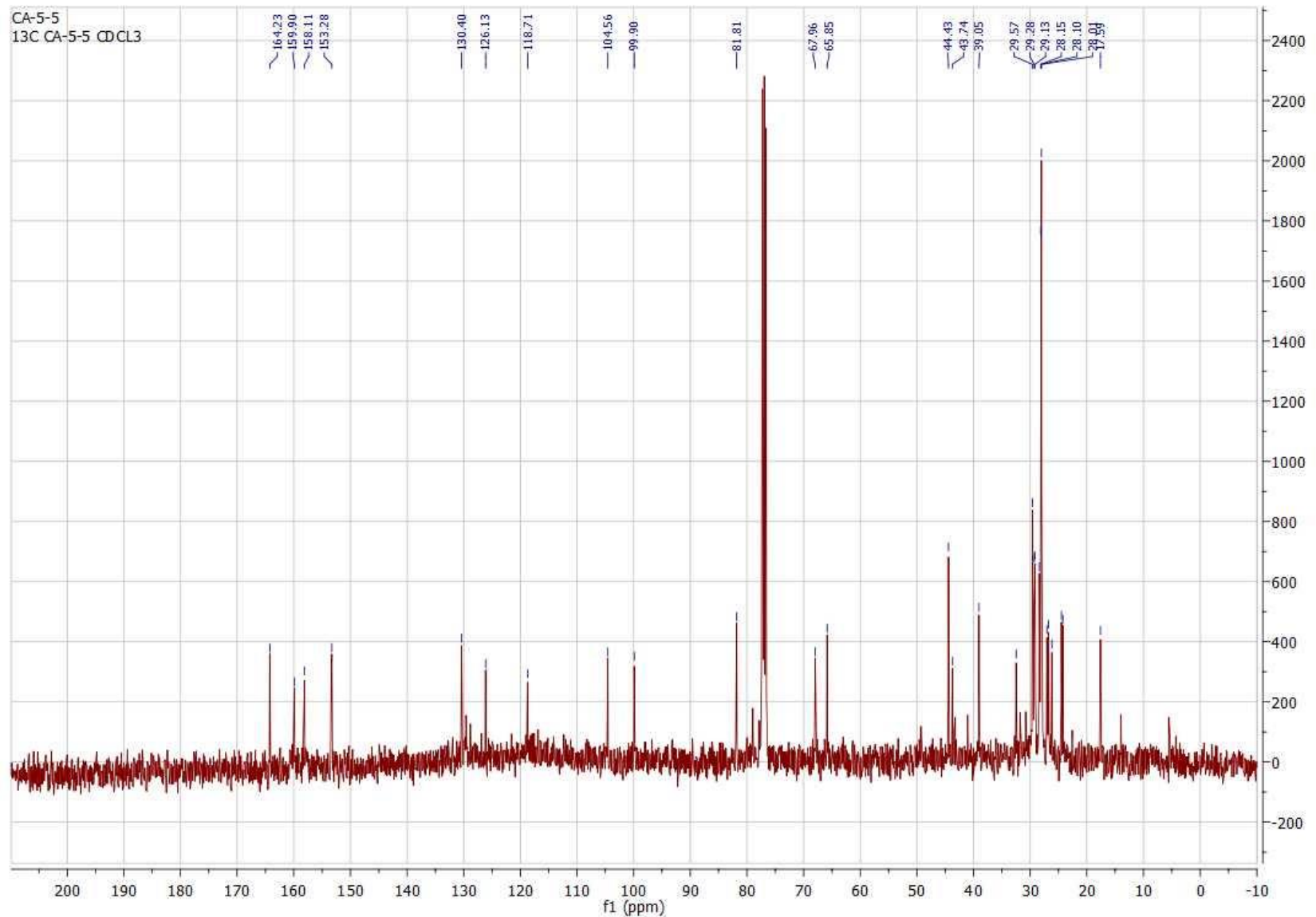


Compound 26, ${ }^{1} \mathrm{HNMR} \mathrm{CDCl}_{3} / \mathrm{MeOD}$
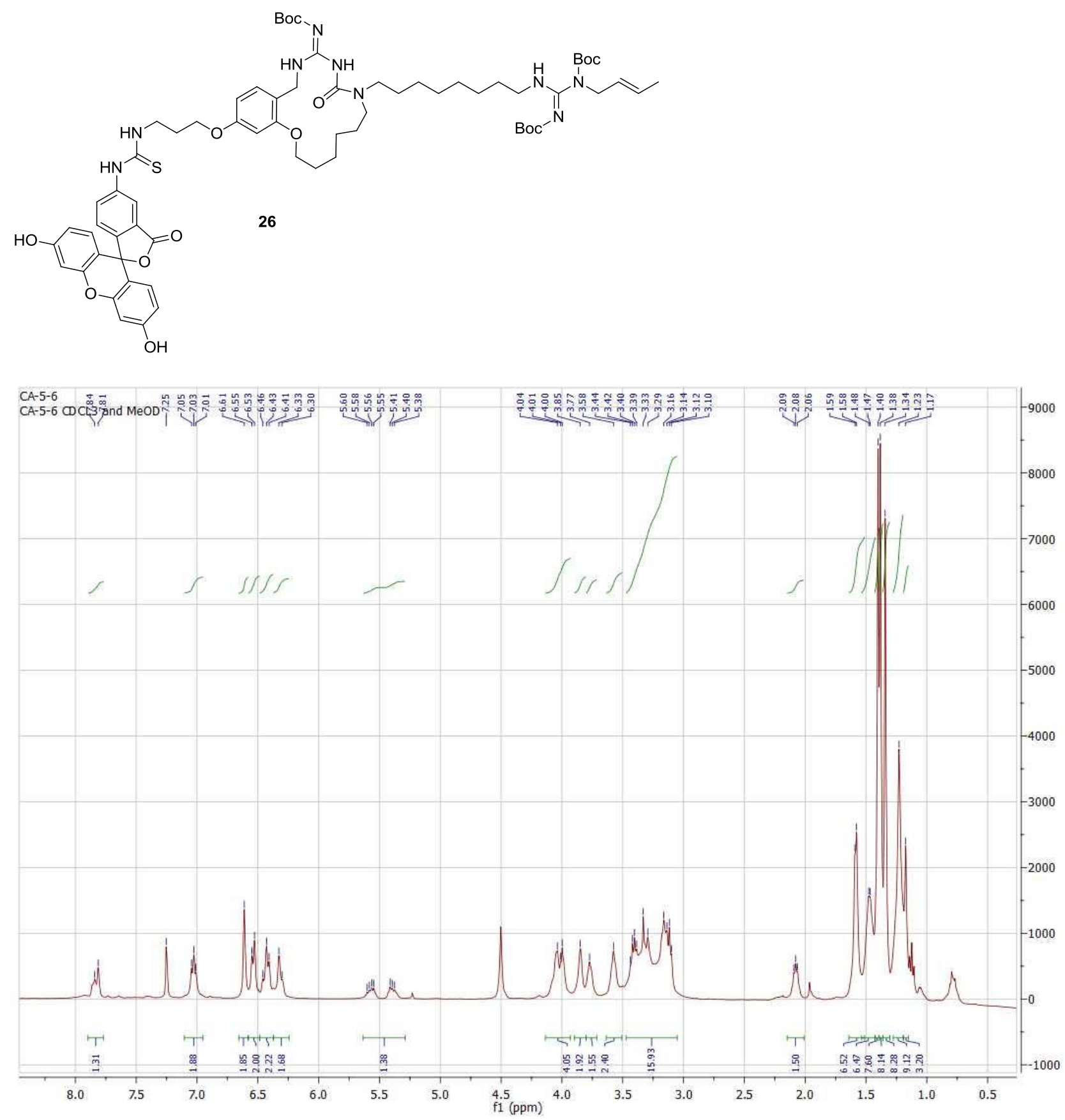


\section{Compound 4, ${ }^{1} \mathrm{HNMR}$ MeOD}
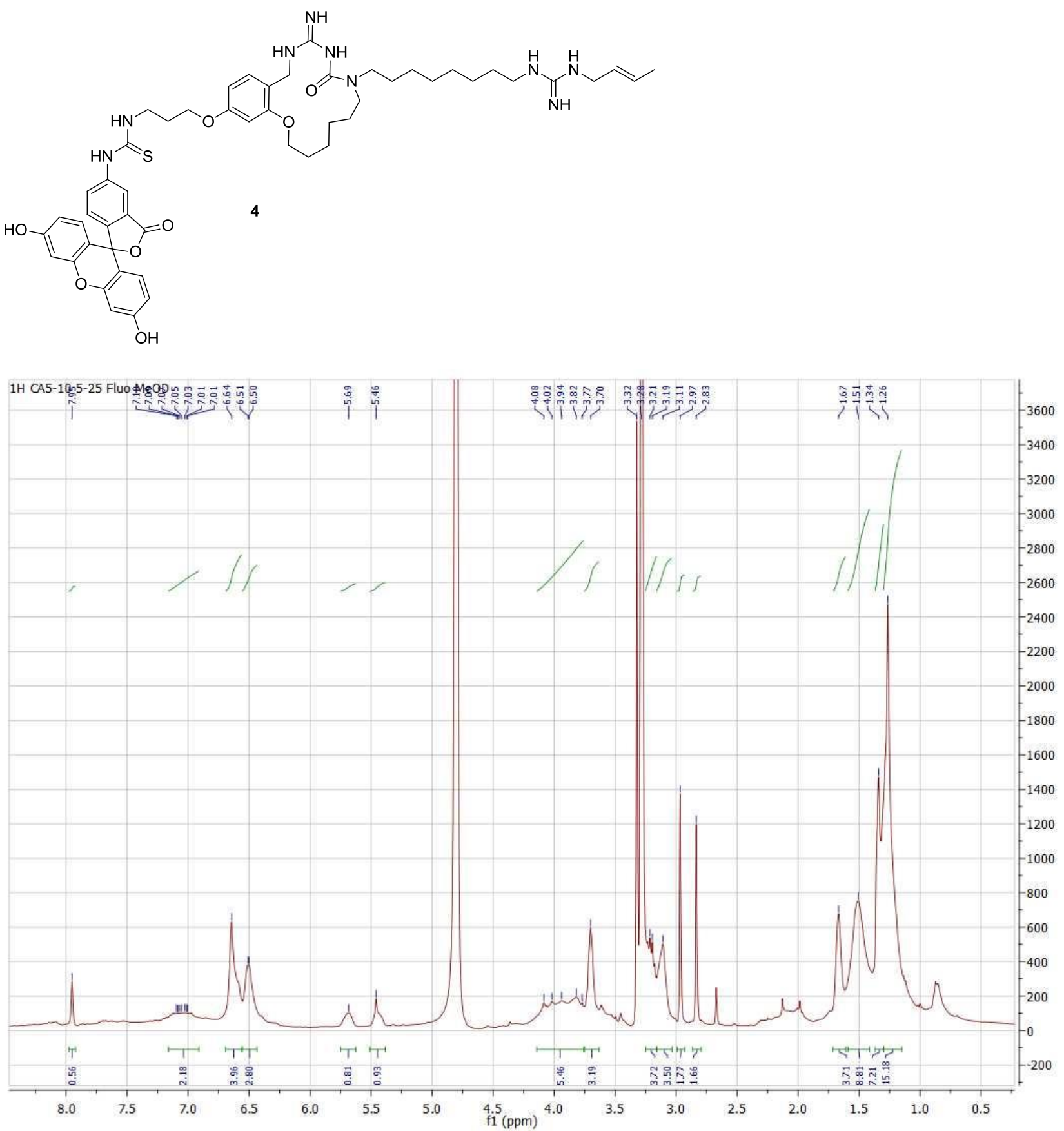
${ }^{13} \mathrm{CNMR} \mathrm{CDCl}_{3} / \mathrm{MeOD}$

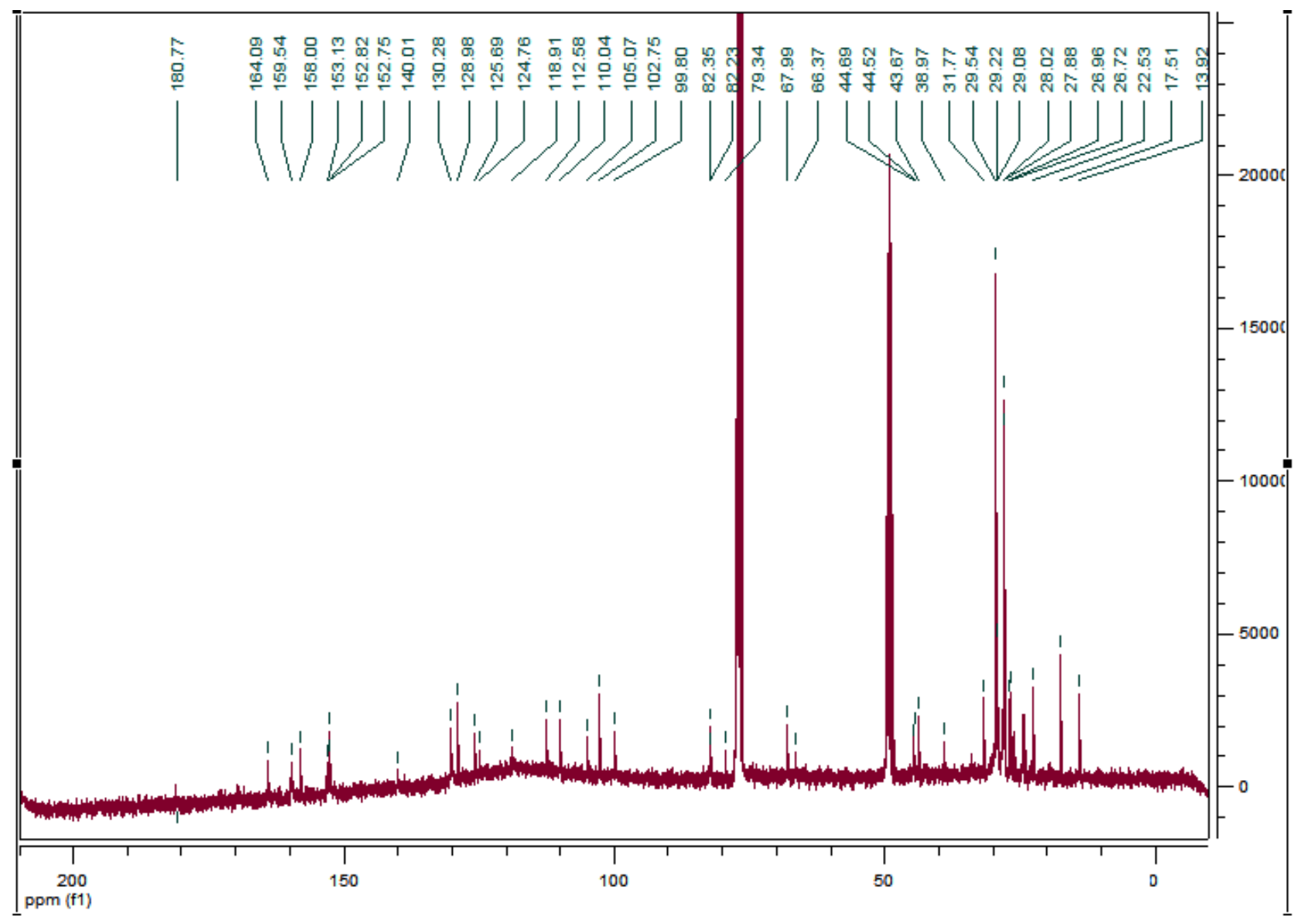

